\title{
Gas-Phase Fragmentation of Cyclic Oligosaccharides in Tandem Mass Spectrometry
}

\author{
Alexander O. Chizhov *, Yury E. Tsvetkov and Nikolay E. Nifantiev \\ N. D. Zelinsky Institute of Organic Chemistry, Russian Academy of Science, Leninskii Prosp., 47, \\ 119991 Moscow, Russia; tsvetkov@ioc.ac.ru (Y.E.T.); nen@ioc.ac.ru (N.E.N.) \\ * Correspondence: chizhov@ioc.ac.ru; Tel./Fax: +7-(499)-135-8784
}

Received: 30 April 2019; Accepted: 11 June 2019; Published: 14 June 2019

\begin{abstract}
Modern mass spectrometry, including electrospray and MALDI, is applied for analysis and structure elucidation of carbohydrates. Cyclic oligosaccharides isolated from different sources (bacteria and plants) have been known for decades and some of them (cyclodextrins and their derivatives) are widely used in drug design, as food additives, in the construction of nanomaterials, etc. The peculiarities of the first- and second-order mass spectra of cyclic oligosaccharides (natural, synthetic and their derivatives and modifications: cyclodextrins, cycloglucans, cyclofructans, cyclooligoglucosamines, etc.) are discussed in this minireview.
\end{abstract}

Keywords: cyclooligosaccharides; cyclodextrins; cyclooligoglucosamines; cyclofructans; cycloglycans; cyclolaminarinoses; cyclosophoraoses; macrocycles; tandem mass spectrometry; electrospray ionization; matrix-assisted; laser-induced desorption/ionization; fragmentation; collision induced dissociation; structure elucidation

\section{Introduction}

Macrocyclic oligosaccharides have been known for a long time. The most studied of them, cyclodextrins (CDs, $\alpha-C D$, cyclohexamaltose, $1 ; \beta-C D$, cycloheptamaltose, $2 ; \gamma-C D$, cyclooctamaltose, 3 , Figure 1), were isolated at the end of 19th century and their cyclic structure (cycles of $\alpha-(1 \rightarrow 4)$-linked glucopyranose units) was firmly established in the middle of the last century (for the history of studies of cyclodextins and their applications, see the excellent review of Crini [1] and references therein).

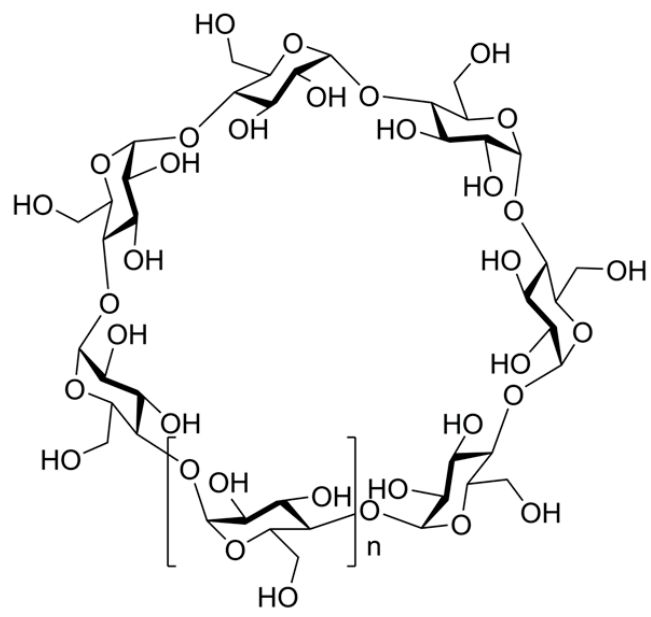

$\mathrm{n}=0, \alpha-\operatorname{CD}(\mathbf{1}) ; \mathrm{n}=1, \beta-\mathrm{CD}(2) ; \mathrm{n}=2, \gamma-\mathrm{CD}(3)$

Figure 1. A general structural formula of $\alpha_{-}, \beta-$, and $\gamma$-cyclodextrins (1-3). 
There are many other carbohydrate macrocycles, both of natural and synthetic origin $[2,3]$. Due to the presence of hydrophobic cavities in $C D$ molecules, these macrocycles and their derivatives are capable to form host-guest inclusion complexes with many organic substances $[4,5]$. This opens possibilities for versatile applications of CDs, for example, for drug delivery of pharmaceutical formulations [5,6], construction of nanomaterials, sugar-based surfactants and food ingredients, preparations for controlled release of fragrances and aromas ([1] and references therein). CDs may be used as antidotes due to selective bonding of toxicants and disease-related metabolites (for example, see [7]: amyloid- $\beta$-peptide related to Alzheimer's disease has strong affinity to $\beta-C D$, and hydroxypropyl- $\beta-C D$ reduces its cell toxicity in model experiments). Mass spectrometry has enormous sensitivity thus allows to use this method for the analysis of trace amounts of drugs, metabolites, xenobiotics, etc. Soft ionization methods (primarily, ESI and MALDI) make possible to transfer heavy, polar molecules into the gas phase. This achievement has opened a way for complementary, mass spectrometric approaches [8] for gas-phase studies of macrocycles (including CDs) in addition to NMR, UV/Vis spectroscopy, circular dichroism, chromatography, etc. used for liquid phase studies [4]. In this review, we have attempted to present the current state of knowledge of mass spectrometry (MS) of cyclic oligosaccharides (cyclodextrins, cyclofructans, cyclo-oligosophoraoses, cyclooligolaminarioses, cyclooligoglucosamines and mixed cyclic oligosaccharides) and to discuss some problems arising from the peculiarities of their structures.

\section{First- and Second-Order Mass Spectra of Cyclic Oligosaccharides and Their Derivatives}

\subsection{Mass Spectrometry of Cyclic Oligosaccharides-General Aspects}

Oligosaccharides (OSs) are non-volatile, thermally unstable compounds so they cannot be analyzed directly by electron ionization (EI) mass spectrometry. Derivatization of oligosaccharides has limited applications, although OS derivatives were used in earlier EI MS studies [9]. FAB, and, later, ESI and MALDI make possible to obtain good quality mass spectra of OS [8,9]. For cyclodextrins, the use of FAB MS [10], and later ESI [11] (named as "ion evaporation atmospheric-pressure ionization mass spectrometry") has been reported. A year later, an extensive study of electrospray (named as "ion spray", IS) MS has been done for intact and partially alkylated, partially acylated $\alpha-, \beta-$, and $\gamma$-CDs using pure solvents and inorganic dopants (salts) in a positive ion mode [12]. In this paper, the first attempt to measure second-order mass spectrum of CD derivative was figured out (as can be seen from Figure 8, bottom, in [12], this attempt almost failed. Recalculation revealed that the $\alpha-$, not the $\beta-C D$ derivative was taken, so the figure legend is erroneous). It was found that under electrospray conditions, intact CDs afford adducts with alkaline metal ions (singly charged) or alkali-earth and transition metal ions (multiply charged) along with $[\mathrm{M}+\mathrm{H}]^{+}$; multiply charged adducts with alkali metal ions were reported for alkylated/acylated derivatives [12]. Indeed, alkali metal ions and protons also give multiply charged ions with intact $\mathrm{CDs}$, for systematic studies including determination of binding constants of $\mathrm{CDs}$ with $\mathrm{Li}^{+}, \mathrm{Na}^{+}, \mathrm{K}^{+}, \mathrm{Rb}^{+}$, and $\mathrm{Cs}^{+}$, see [13]. Ammonium can also form complexes with CDs, thermodynamics of this process was studied using FT ICR MS and molecular modeling [14]. Overlap of peak clusters of the ions bearing different charges (Figure 2) was reported in several papers, e.g. $[15,16]$. The separation of these ions (for example, $[\mathrm{M}+\mathrm{H}]^{+}$and $[2 \mathrm{M}+2 \mathrm{H}]^{2+}$ ) by mass spectrometry alone is impossible (because of $m / z=n m / n z$ ), but they are separable by ion mobility spectrometry (IMS) due to their difference in size and shape $[17,18]$.

In MALDI MS, CDs give only singly charged ions. For example, for permethylated $\beta-C D$ in DHB matrix, only $[\mathrm{M}+\mathrm{Na}]^{+}$ion was observed in a special ultrahigh-resolution MS experiment in a positive ion mode [19]. However, there is a pitfall in the interpretation of MALDI MS of some intact and derivatized OSs, especially of CDs, which are prone to form complexes; the phenomenon of association of OSs with DHB matrix was studied [20]. It was found that all intact CDs form adducts [M + DHB $\mathrm{H}]^{-}$in a negative ion mode and totally or partially methylated $\beta$-CDs form adducts $[\mathrm{M}+\mathrm{DHB}+\mathrm{Na}$ (or K) $]^{+}$in a positive ion mode. 

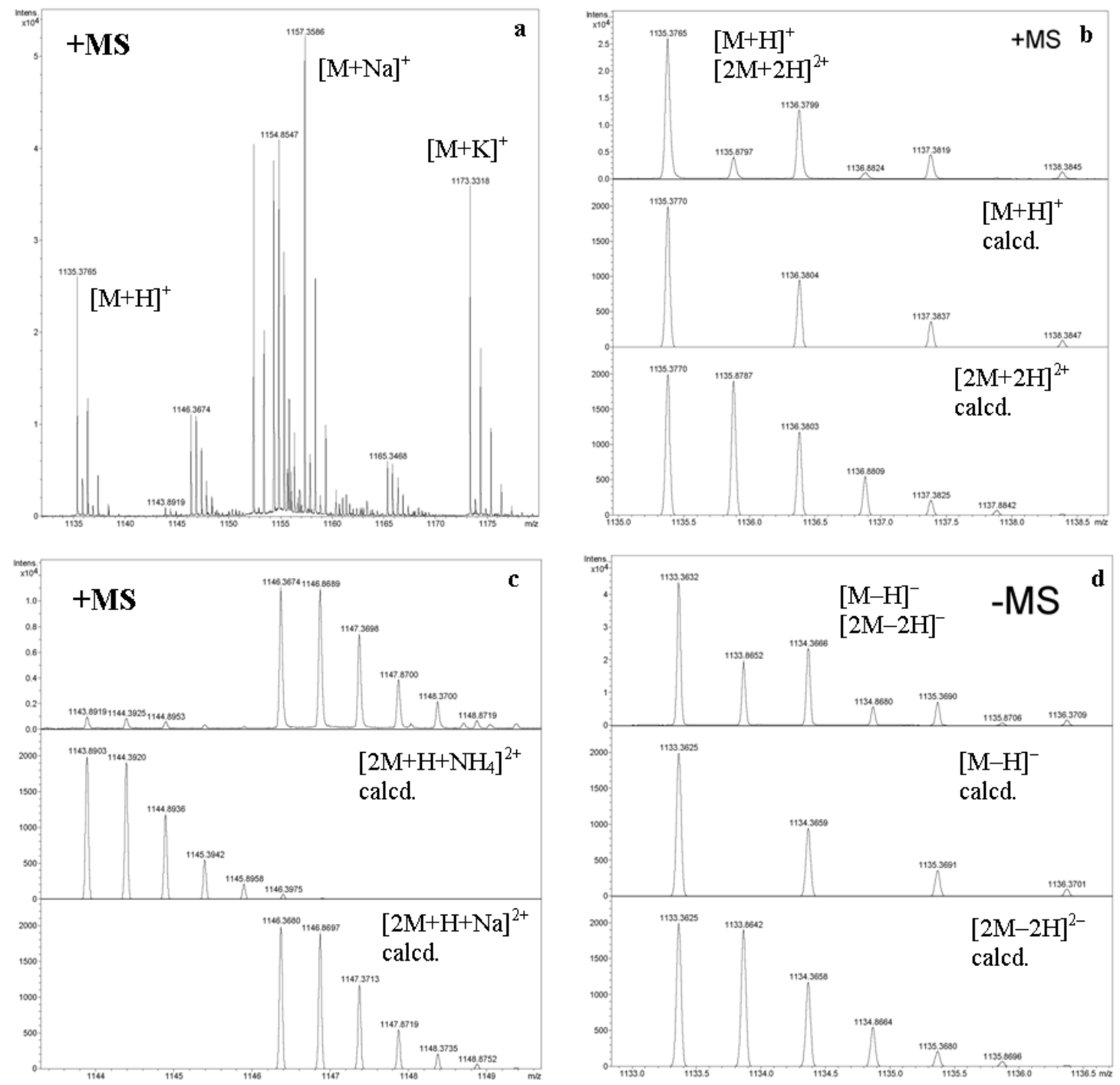

Figure 2. High-resolution ESI mass spectra of $\beta-C D$ (the authors' data). (a) Positive ion mode, range $m / z$ 1130-1180; (b) same, extension $\mathrm{m} / \mathrm{z}$ 1135-1138.7, (c) same, extension $\mathrm{m} / \mathrm{z}$ 1143-1150; (d) Negative ion mode, range $m / z$ 1133-1136.5. calcd.: simulated profiles of isotopic clusters.

Cyclofructans $(\mathrm{CFs})$, isomers of $\mathrm{CDs}$, are the second class of carbohydrate macrocycles. The most studied of them are hexakis- $\beta-(2 \rightarrow 1)$-fructofuranose $(\mathrm{CF} 6,4)$, heptakis- $\beta-(2 \rightarrow 1)$-fructofuranose (CF7, $5)$, octakis- $\beta$ - $(2 \rightarrow 1)$-fructofuranose $(\mathrm{CF} 8,6)$ (Figure 3). In ESI positive ion mode mass spectra, permethylated CFs associate with alkali-metal ions, for $\mathrm{CF}$, the affinity changes in order of $\mathrm{K}^{+}>\mathrm{Rb}^{+}$ $>\mathrm{Cs}^{+}>\mathrm{Na}^{+}$, for CF7, $\mathrm{Rb}^{+}>\mathrm{K}^{+}>\mathrm{Cs}^{+}>\mathrm{Na}^{+}$(solutions in acetone) [21]. Intact CFs also form 1:1 aggregates with alkali metal ions (for extensive ESI MS and DFT molecular modeling studies see [22]). CFs possesses hydrophobic cavities (however, not as prominent as those of CDs) and, hence, are capable of forming inclusion complexes with hydrophobic compounds, e.g., amino acids [23] (compare to CDs: [24-26]), so despite a different carbohydrate composition, CDs and CFs have similar properties.

A general problem of all mass spectrometric studies of non-covalent interactions is the adequate evaluation of relations between condensed and gas phases. Otherwise, how to correlate MS peaks intensities registered for ions in the gas phase and concentrations of non-charged molecules existing in the solution which is injected into the ESI ion source? There are many disclaimers in literature cautioning readers to avoid the so-called "mass spectrometric fanaticism", for example, that it was reported for CD—Trp complexation: all non-1:1 ions observed in ESI MS "are of electrostatic rather than hydrophobic nature" [24]. The discussion of this problem related to comparative study of CDs 
host-guest complexation was presented in [27] by Zenobi and coworkers. Most papers on MS of CD inclusion complexes are reviewed in [28] and recently in [29] (the latter paper being concentrated on chiral recognition).

The influence of the degree of methylation of CDs on the affinity of alkali metal ions towards CDs was studied in [30]. It was shown for intact $\beta-C D$ and variously methylated $\beta$-CDs that the higher the degree of methylation, the higher is the affinity of $\mathrm{Li}^{+}, \mathrm{Na}^{+}$, and $\mathrm{K}^{+}$towards the CDs; selectivity of bonding increases in order of $\mathrm{Na}^{+}>\mathrm{Li}^{+}>\mathrm{K}^{+}$in solution and $\mathrm{Li}^{+}>\mathrm{Na}^{+}>\mathrm{K}^{+}$in the gas phase (CID MS ${ }^{2}$ and $\mathrm{HCD} \mathrm{MS}^{2}$ experiments, DFT molecular modeling).

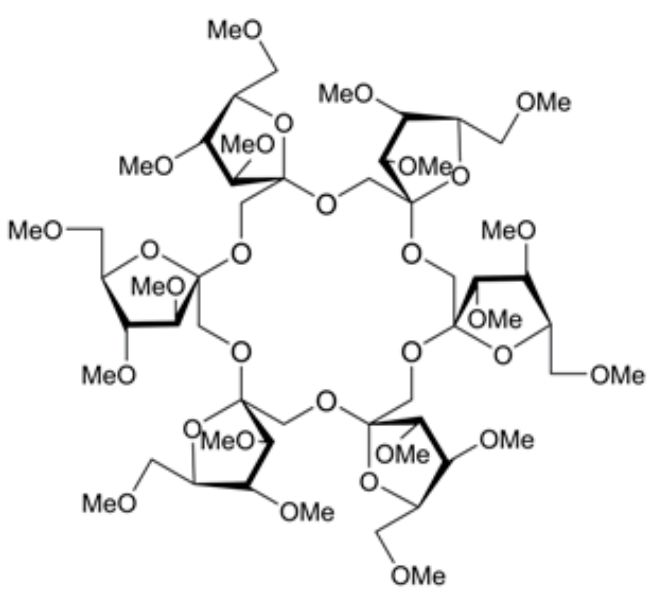

CF6 (4)

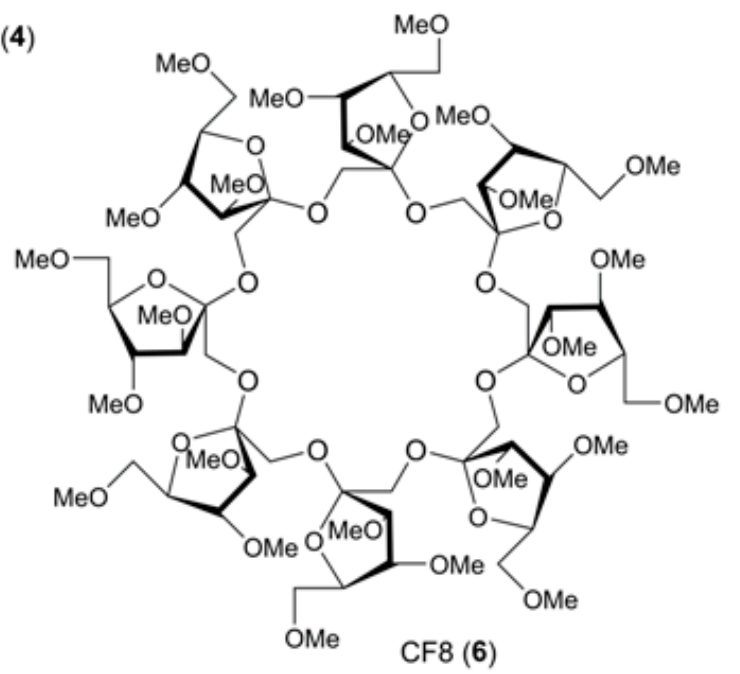

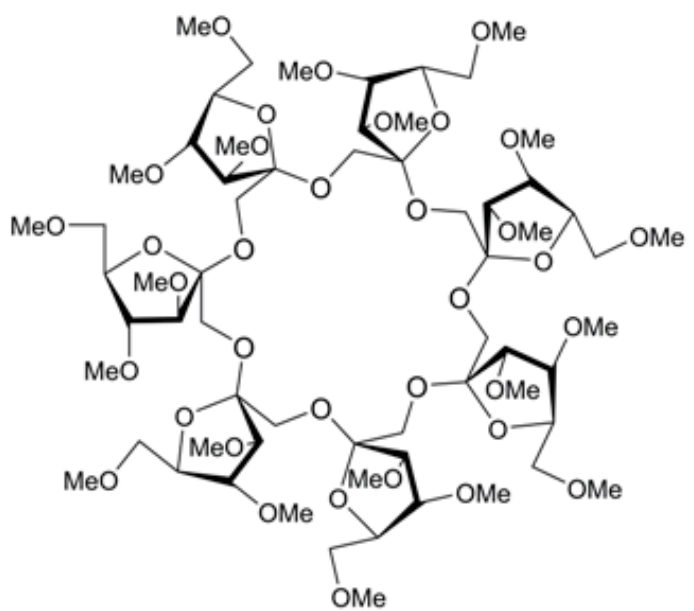

CF7 (5)

Figure 3. Structural formulas of cyclofructans CF6 (4), CF7 (5), and CF8 (6).

ESI MS, and especially MALDI MS, now are widely used for profiling derivatized CDs and determination of their degree of substitution (d.s.). In these profiles, the differences in the homologous peaks correspond to specific increments; e.g., for methylated CDs, this is $14 \mathrm{Da}\left(\mathrm{CH}_{2}\right)$. Profiling of charged $\beta$ - and $\gamma$-CD derivatives, both cationic $\left(\mathrm{Me}_{3} \mathrm{~N}^{+}\left(\mathrm{CH}_{2}\right)^{3-}\right)$ and anionic $\left({ }^{-} \mathrm{O}_{3} \mathrm{~S}\left(\mathrm{CH}_{2}\right)^{\mathrm{n}-}, \mathrm{n}=2\right.$ to 4), was reported for the first time in [31]. Capillary electrophoresis (CE) was taken as an independent method for control, good results were obtained for ESI (IS) and MALDI TOF MS, whereas FAB MS showed inadequate spectra.

\subsection{Tandem Mass Spectra $\left(M S^{n}\right)$ of Unsubstituted Cyclooligosaccharides: General Regularities and Attempt of Description}

There are several papers devoted to the selective fragmentation of protonated and cationized (metallated) molecules of cyclodextrins (cations) [32-37] and deprotonated molecules (anions) [38]. 
CID MS ${ }^{2}$ spectra of associates of CDs with following cations were studied: $\mathrm{Li}^{+}$[32,34], $\mathrm{Na}^{+}[33,36]$, $\mathrm{Mg}^{2+}, \mathrm{Ca}^{2+}, \mathrm{Cd}^{2+}, \mathrm{Co}^{2+}, \mathrm{Cu}^{2+}, \mathrm{Pb}^{2+}[33], \mathrm{Th}^{4+}, \mathrm{Ce}^{3+}[35], \mathrm{NH}_{4}{ }^{+}$[37]. For all cations, singly or multiply charged, the consecutive losses of $162 \mathrm{Da}$ (Glc $p$ unit) or, in less extent, for multiply charged ions, losses of $264 \mathrm{Da}\left(\mathrm{C}_{10} \mathrm{H}_{16} \mathrm{O}_{8}\right)$ were observed. The former neutral loss occurs definitely due to glycosidic bond(s) cleavage, whereas the latter one apparently involves interresidue cleavage (i.e., the rupture of the $\mathrm{C}-\mathrm{C}$ bonds in the carbohydrate unit) $[33,35]$. For cyclofructans $\mathrm{CF} 6$ and $\mathrm{CF} 7$, formation of $[\mathrm{CF}-\mathrm{H}$ $+\mathrm{Cat}]^{+}$ions $\left(\mathrm{Cat}=\mathrm{Fe}^{2+}, \mathrm{Co}^{2+}, \mathrm{Ni}^{2+}, \mathrm{Cu}^{2+}\right.$, and $\mathrm{Zn}^{2+}$ ) was observed when using aqueous methanol, acetone and acetonitrile solutions for ESI MS; their CID resulted in sequential loss of Fruf units (peak difference in $162 \mathrm{Da}$, the most abundant series), ions of the second (less abundant) series were on $18 \mathrm{Da}$ $\left(\mathrm{H}_{2} \mathrm{O}\right)$ heavier [39].

Typical CID MS² spectra (QqTOF instrument, acetonitrile: $\mathrm{H}_{2} \mathrm{O}, 50: 50$ vol. \%) of ions generated from $\alpha-C D$ are presented in Figure 4 (here and below, all calculations of $m / z$ were done by us using Compass Data Analysis 4.0 ${ }^{\circledR}$, or an Isotope Pattern application, Bruker Daltonics, Bremen, FRG).

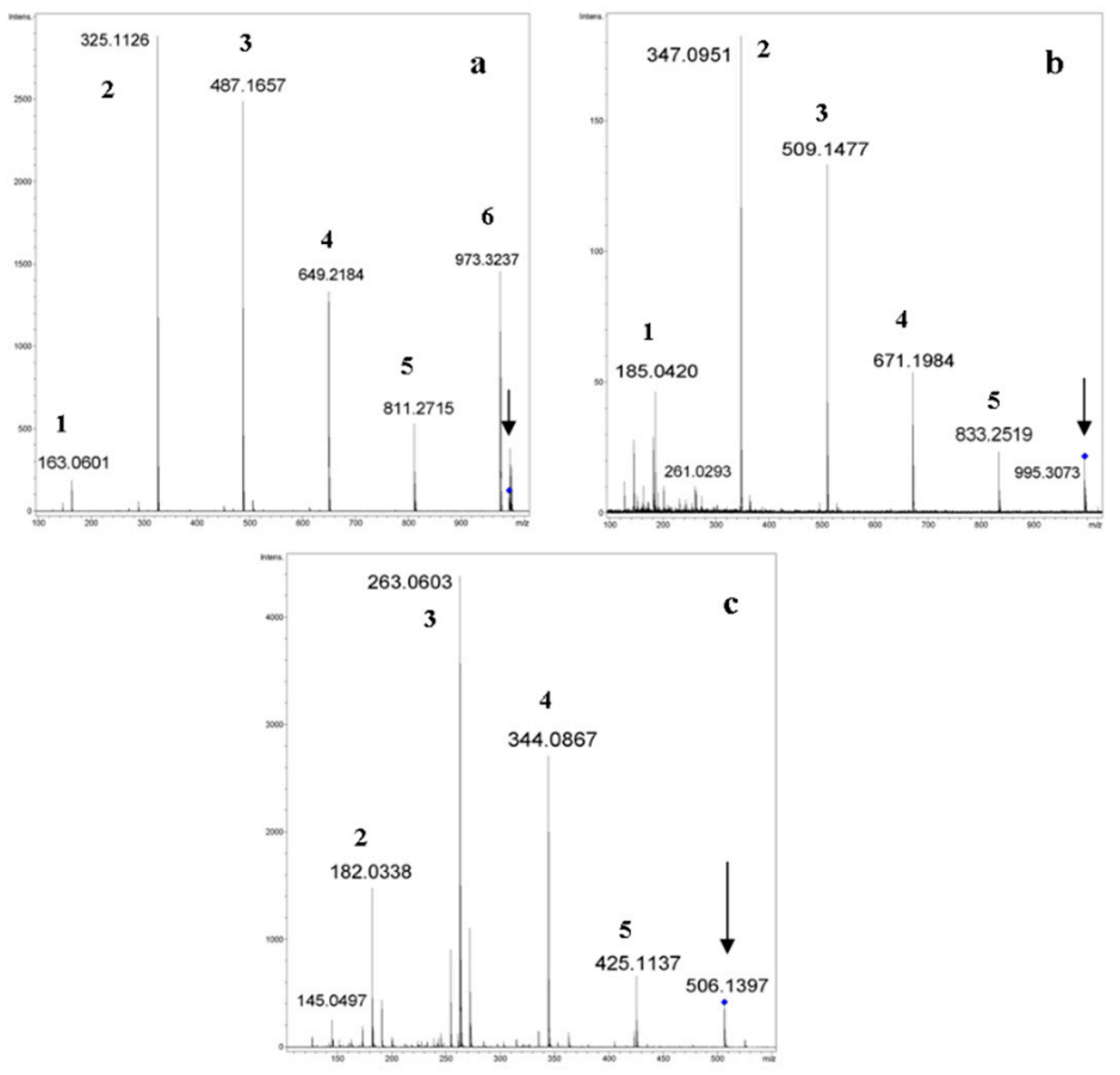

Figure 4. Tandem $\left(\mathrm{CID} \mathrm{MS}^{2}\right)$, high-resolution ESI mass spectra of selected ions generated from $\alpha$-CD (the authors' data). Fragmented ions (marked by arrows): (a) $\left[\mathrm{M}+\mathrm{NH}_{4}\right]^{+}, m / z 990$, c.e. $15 \mathrm{eV}$; (b) $[\mathrm{M}+$ $\mathrm{Na}]^{+}, m / z 995$, c.e. $65 \mathrm{eV}$; (c) $[\mathrm{M}+\mathrm{H}+\mathrm{K}]^{2+}, m / z 506$, c.e. $20 \mathrm{eV}$. The numbers mean the amount of Glc residues in the fragments $\left[\mathrm{Glc}_{\mathrm{n}}+\mathrm{H}\right]^{+},\left[\mathrm{Glc}_{\mathrm{n}}+\mathrm{Na}\right]^{+}$, and $\left[\mathrm{Glc}_{\mathrm{n}}+\mathrm{H}+\mathrm{K}\right]^{2+}$, respectively.

It is impossible to find out "reducing" and "non-reducing" ends for a cyclic oligosaccharide molecule (as well as, in general, there is no beginning/end of any ring), so an attempt to apply the generally accepted Domon-Costello nomenclature of oligosaccharide fragmentation [40] leads to confusion. For example, the authors of [32] referred to [40] and assumed that $[\mathrm{M}+\mathrm{Li}]^{+}$and $[\mathrm{M}+2 \mathrm{Li}]^{2+}$ "fragment by glycosidic cleavages giving B-series of ions..." (note that similar B-series were claimed in [15]), though these fragments (neutral losses of $162 \mathrm{Da}$, glucose units) may be assigned to Y-type 
(or Z-type) on the same basis, as reported in the text of the paper [33]: “...we believe that the loss of mass 162 proceeds according to the Y-type ion formation" [33] (p. 1568, left column, also see Scheme 1, p. 1570 reprinted here as Figure 5). The same Domon and Costello paper [40] was referenced. In contrast to the above suggestions, the authors in the same paper [33] introduced new designations of $\mathrm{A}, \mathrm{B}, \mathrm{C}$, and D-series for fragmentations of doubly charged cations $[\mathrm{M}+\mathrm{Cat}]^{2+}$ (Cat is divalent metal cation, QqTOF mass spectrometer, collision energy, c.e. 25-35 eV) in the table of the $\mathrm{MS}^{2} \mathrm{~m} / \mathrm{z}$ data and presented a description of them below the table. Briefly, A-series is formed by doubly charged ions differed in 81 Th. B-series arises due to charge separation reaction due to loss of [Glc $+\mathrm{H}^{+}$(difference in $162 \mathrm{Da}$ ). Low abundant C-series is formed by singly charged ions smaller than B-peaks on $264 \mathrm{Da}$; this cleavage is accompanied by C-H hydrogen transfer (demonstrated by H/D isotopic exchange in $\mathrm{OH}$ groups). Low abundant D-series may be regarded as a result of loss of $\mathrm{H}_{2} \mathrm{O}$ from B-series ions (not observed for $\mathrm{Co}, \mathrm{Cu}$, and $\mathrm{Pb}$ additives). For a representative $\mathrm{MS}^{2}$ spectrum, see Figure 6, one can conclude that this is an ad hoc classification poorly related to the Domon-Costello nomenclature; only "B-ions" has a weak similarity to B-series stated in [40]. Unfortunately, the survey of the literature has shown that there is no adequate, general nomenclature to describe the cleavages for cyclic oligosaccharide ions (see Section 2.5).

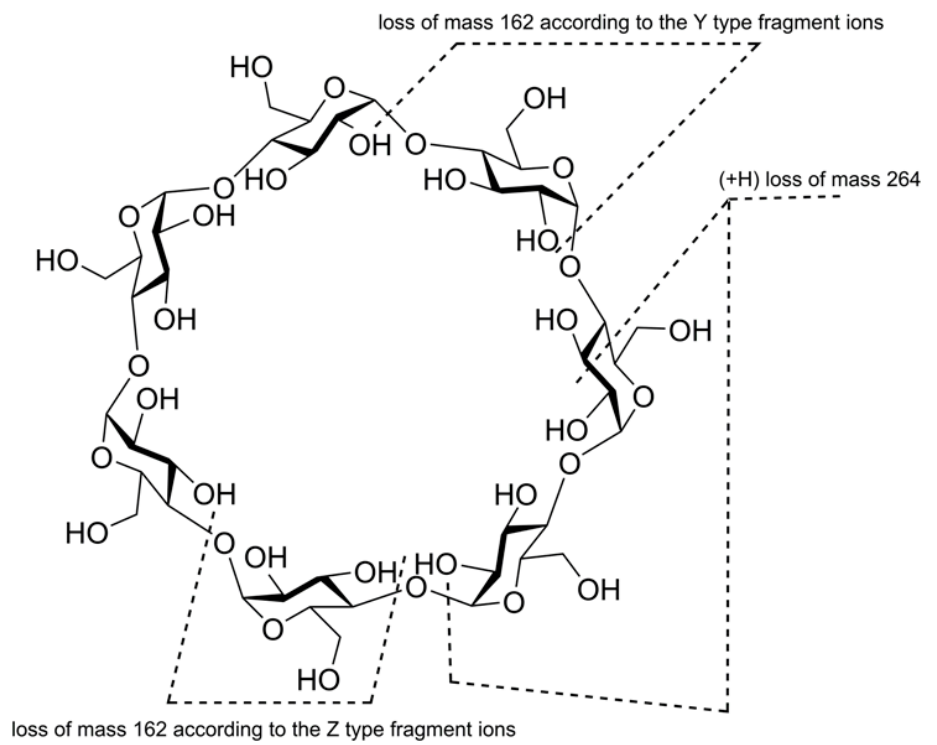

Figure 5. Fragmentation of $[\beta-C D+C a t]^{2+}$ ions according to [33].

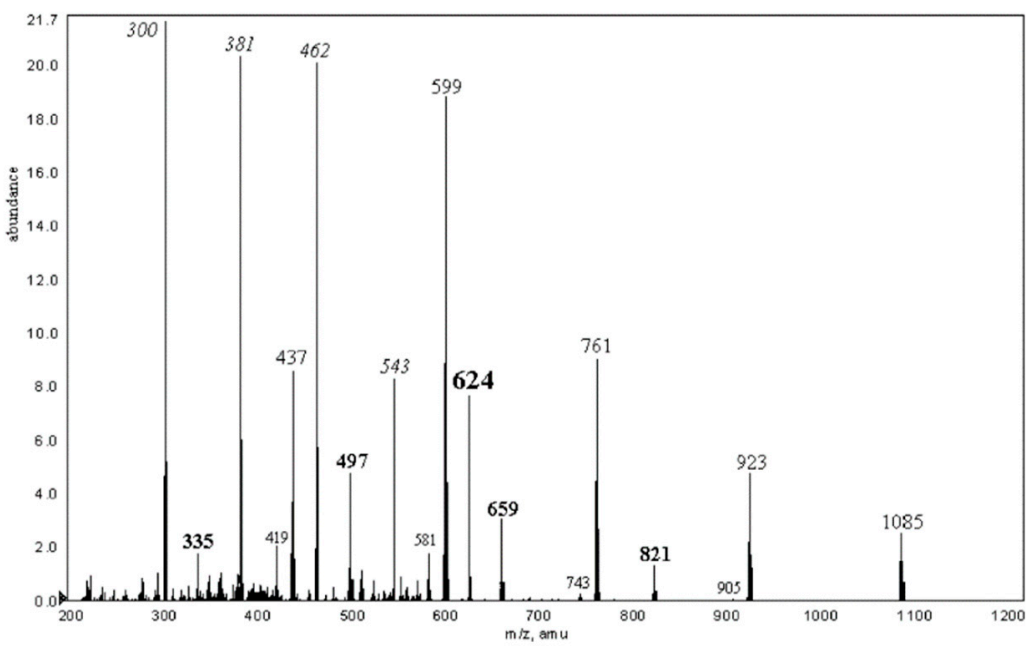

Figure 6. $\mathrm{CID} \mathrm{MS}^{2}$ of $[\beta-\mathrm{CD}+\mathrm{Cd}]^{2+}$ ion at $m / z 624$ (reproduced from [33] with permission of Elsevier). 


\subsection{The Difference in Mass Spectra of Cyclic and Acyclic Oligosaccharides}

\subsubsection{FAB MS, MALDI TOF MS, and ESI MS of Cyclic Oligosaccharides}

One of the applications of MS to structure elucidation of OSs is the determination of their acyclic (the most common) or cyclic (more rare) nature. Of course, acyclic or cyclic OS may be branched or carry side chains. Cyclic OS are lighter than the corresponding acyclic OS by a definite increment; for underivatized OSs, this is $\mathrm{H}_{2} \mathrm{O}(\mathrm{ca} .18 \mathrm{Da})$, for permethylated $\mathrm{OSs}_{2} \mathrm{C}_{2} \mathrm{H}_{6} \mathrm{O}(\mathrm{ca}$. $46 \mathrm{Da})$, for peracetylated OSs, $\mathrm{C}_{4} \mathrm{H}_{6} \mathrm{O}_{3}(\mathrm{ca} .102 \mathrm{Da})$, etc. Note, that the MS of acyclic OS having an anhydro unit in its composition looks like that of cyclic one due to their isomerism. Some structural studies based on MS (along with NMR) are presented below. A previously unknown glucan (classified by its function as osmoregulated periplasmic glucan, OPG) was isolated from a recombinant strain of a Rhizobium meliloti TY7, an ndvB mutant carrying a locus specifying $\beta-(1 \rightarrow 3,1 \rightarrow 6)$ glucan synthesis from Bradyrhizobium japonicum USDA110, using reversed phase chromatography [41]. The compound was of carbohydrate nature free of phospholipid moieties usual for Rhizobia. FAB MS of the oligosaccharide showed peaks at $m / z 1945$ and $m / z$ 1967, which were assigned to $[\mathrm{M}+\mathrm{H}]^{+}$(calcd. $m / z$ 1945.6) and $[\mathrm{M}+\mathrm{Na}]^{+}\left(\right.$calcd. $m / z$ 1967.6), respectively $\left(\mathrm{M}=\mathrm{Glc}_{12}\right)$. Acyclic dodecahexaose should be heavier by $18 \mathrm{Da}$, so, this one had likely a cyclic structure. ${ }^{1} \mathrm{H}$ - and ${ }^{13} \mathrm{C}-\mathrm{NMR}$ spectra were rather complex, but they demonstrated the presence of mainly $\beta-(1 \rightarrow 3)$-linked (definitely not of $\alpha$-configuration) glucose residues along with a minor $\beta-(1 \rightarrow 6)$-glycosidic bond. The first Smith degradation afforded the product consisting of eleven hexose units (FAB MS $m / z 1783,[\mathrm{M}+\mathrm{H}]^{+}$, calcd. $m / z$ 1783.6, and $m / z$ 1805, $[\mathrm{M}+\mathrm{Na}]^{+}$, calcd. $m / z$ 1805.6). The second Smith degradation gave the product consisting of only $\beta-(1 \rightarrow 3)-G l c p$ units according to ${ }^{1} \mathrm{H}$ - and ${ }^{13} \mathrm{C}$-NMR spectra (i.e., this is cyclodekakis- $(1 \rightarrow 3)-\beta$-glucosyl), which was resistant to the next Smith degradation. Surprisingly, the MS of this carbohydrate expected to be cyclodecalaminarinose exhibited the main peak at $m / z 1735$, which the authors assigned it to $[\mathrm{M}+5 \mathrm{Na}]^{+}$, which is definitely unbelievable. A more reasonable explanation of this peak is complexation of the analyte with glycerol usually used as a FAB matrix (although thioglycerol and $m$-nitrobenzoic acid were reported as matrices in the Experimental part), for $\left[\mathrm{Hex}_{10}+\mathrm{Gro}+\mathrm{Na}\right]^{+}$, calculation gives $m / z$ 1735.56, so the structure of the starting material was assigned to $\beta$ - $(1 \rightarrow 6)$-laminaro(cyclodekakis- $\beta$ - $(1 \rightarrow 3)$-glucosyl). Later, the same authors isolated the both cyclic OSs (branched, cyclic dodecasaccharide and cyclic decasaccharide) from different mutants of Bradyrhizobium japonicum [42]. At the same time, an extensive FAB and MALDI MS study of laminarans (reserve $\beta-(1 \rightarrow 3,1 \rightarrow 6)$-glucans from brown algae) was performed [43]. It was found for laminarans from Chorda filum and Cystoseira crinita, that some peaks in MALDI MS of these native laminarans were accompanied by "minus $18 \mathrm{Da}^{\prime}$ satellites and the corresponding peaks in MALDI MS and FAB MS were accompanied by "minus 46 Da" ones. Because other laminarans (both G-chains, i.e., with free reducing end, and M-chains, terminated with $\beta-(1 \rightarrow 1)$-linked mannitol) did not demonstrate a loss of water under MALDI conditions, the authors proposed the occurrence of macrocyclic structures in these laminarans. Since no experiments to find out independent proofs were done, the precaution "Whether the cyclic components are macrocycles or have an anhydro sugar at the reducing end remains to be established" was stated [43]. This remains true until now.

Similar studies were carried out for OPGs from several agriculturally important microorganisms (symbiotic, e.g., Rhizobia, nitrogen-fixing bacteria, or parasitic, like Xantomanas campestris, responsible for black rot of cruciferous plants). An earlier application of FAB MS done by Dell, was to establish cyclic structures of $\beta-(1 \rightarrow 2)$-linked glucans (d.p. from 17 to 24 , cyclosophoraoses) isolated from Rhizobia and Agrobacteria. It was shown by ${ }^{13} \mathrm{C}-\mathrm{NMR}$ that these cyclic structures are homogeneous $(\beta-(1 \rightarrow 2)-G l c p$ units only) and unbranched [44]. Later, two other cyclic OPGs were isolated from Bukholderia solanacearum and Xantomonas campestris pv. citri [45]. Their cyclic structures were demonstrated successfully by MALDI TOF MS: the main peaks both assigned to $[\mathrm{M}+\mathrm{Na}]^{+}$, were at $m / z 2129.7$ (calcd. for [Glc $\left.{ }_{13}+\mathrm{Na}\right]^{+} \mathrm{m} / z$ 2129.67, B. solanacearum) and $\mathrm{m} / z 2616.8$ (calcd. for [Glc 16 $+\mathrm{Na}]^{+} \mathrm{m} / \mathrm{z} 2616.84$, the second peak in isotopic cluster having $100 \%$ abundance, X. campestris), 
respectively. The ions $[\mathrm{M}+\mathrm{K}]^{+}$were mentioned with no data. Heterogeneity of these cycles (the presence of one $\beta-(1 \rightarrow 6)-G l c p$ units inside each cycle) was approved by NMR spectrometry $\left({ }^{1} \mathrm{H}\right.$ - and ${ }^{13} \mathrm{C}-\mathrm{NMR}$, including $2 \mathrm{D}$ procedures) and molecular dynamics calculations. Cyclic OPGs usually bear side chains, e.g., phosphatidylglycerols giving a $+\mathrm{C}_{3} \mathrm{H}_{7} \mathrm{O}_{5} \mathrm{P}$ increment (ca. 154 Da each) [46]. In this paper, two glycerophosphorylated $\alpha$-cyclosophorohexadecaoses $\left(\mathrm{M}_{1}\right.$, monophosphorylated, $\mathrm{M}_{2}$ diphosphorylated) were isolated from a different stain of X. campestris and characterized by MALDI MS in a positive ion mode and by ESI MS in a negative ion mode. For MALDI MS (DHB matrix), the following data were presented: $m / z 2792.7,\left[\mathrm{M}_{1}-\mathrm{H}+2 \mathrm{Na}\right]^{+}$, calcd. $m / z 2792.8$ (for all, the most abundant second peak in the cluster), $m / z$ 2969.1, $\left[\mathrm{M}_{2}-2 \mathrm{H}+3 \mathrm{Na}\right]^{+}$, calcd. $m / z$ 2968.80. In ESI MS, the main triply and doubly charged ions were observed: $m / z$ 915.9, $\left[\mathrm{M}_{1}-3 \mathrm{H}\right]^{3-}$ (calcd. $m / z$ 914.9433); $m / z 967.7\left[\mathrm{M}_{2}-3 \mathrm{H}\right]^{3-}$, (calcd. $m / z$ 966.2777); $m / z$ 1374.6, $\left[\mathrm{M}_{1}-2 \mathrm{H}\right]^{2-}$ (calcd. 1372.42), $\mathrm{m} / \mathrm{z} 1451.6$, $\left[\mathrm{M}_{2}-2 \mathrm{H}\right]^{2-}$ (calcd. 1449.92). There is no explanation why the exp./calcd. data coincidence for ESI MS was not so good as for MALDI TOF MS, possibly, this due to low resolution of the triple quadrupole analyzer used in this work. No MS ${ }^{2}$ data were reported.

The appropriate side chain (e.g., possessing specific affinity) can be introduced artificially. Biotinylation through amidocaproyl spacer was done by Cho et al. [47]. A mixture of cyclooligosophoraoses from Rhizobia (d.p. 17 to 22) were selectively monotosylated at C-6, subjected to azidation followed by reduction with $\mathrm{PPh}_{3}$ in DMF, and the purified amine was acylated with biotinamidohexanoic acid $N$-hydroxysuccinimide ester. MALDI TOF MS (DHB matrix) of monoaminated and monobiotinylated cyclooligosophoraoses displayed prominent $[\mathrm{M}+\mathrm{Na}]^{+}$peaks for d.p. 17 to 22 which showed good coincidence with the calculated values. As expected, the difference between the corresponding peaks with the same d.p. is equal to ca. $339 \mathrm{Da}$ (the total mass of biotin moiety and caproyl linker, $\mathrm{C}_{16} \mathrm{H}_{25} \mathrm{~N}_{3} \mathrm{O}_{3} \mathrm{~S}$, 340 Da was reported in the paper).

\subsubsection{Cyclic and Acyclic Oligosaccharides: Differences in Affinities to Metal Cations}

One can suppose than there are differences in the affinities to alkali metal cations (or other cations) between linear and cyclic oligosaccharides. In fact it was shown by Choi et al. [48] that the relative ion intensities of $\alpha-\mathrm{CD}$ and $\beta-\mathrm{CD}$ associates with $\mathrm{Na}^{+}, \mathrm{K}^{+}$, and $\mathrm{Cs}^{+}\left(\right.$not $\left.\mathrm{H}^{+}\right)$in MALDI MS were much higher that of corresponding ionized maltohexaose and maltoheptaose, respectively; differences showed an increasing trend with the radii of metal cations, and $\beta-C D$ had higher ionization efficiency than $\alpha-C D$. However, no proofs of general character of this regularity were demonstrated and even if such proofs will be found, it seems problematic to use this phenomenon in assignment of isomeric acyclic and cyclic OSs without authentic or reference samples (cf. [43]).

\subsubsection{Cyclic and Linear Oligosaccharides: Differences in Tandem Mass Spectra}

To use fragmentation techniques to distinguish linear and cyclic OSs is promising in order to avoid isolation of individual compounds. The first attempt to realize this approach was done by P.J. Derrick and colleagues [49]. Dextran, maltodextrin, and $\gamma$-CD were subjected to in-source decay (ICD) under MALDI MS. Of course, these gluco-OSs have different linkages and different secondary structures, nevertheless, the distinction in degrees of fragmentation clearly correlated with degree of freedom in saccharide chains (determined for solutions by NMR). For $\gamma-C D$, fragmentation was negligible even at elevated laser power in contrast to acyclic OSs, especially dextran which was fragmented the most. Maltodextrin had an intermediate degree of fragmentation.

Later, a similar regularity was demonstrated for ESI MS in more sophisticated experiment using $\mathrm{CID}, \mathrm{PQD}$, and HCD activation procedures for three pairs of $\alpha-\mathrm{CD} /$ maltohexaose, $\beta-\mathrm{CD} /$ maltoheptaose and $\gamma-\mathrm{CD} /$ maltooctaose [50]. A LTQ orbitrap hybrid instrument was used and $[\mathrm{M}+\mathrm{Na}]^{+}$and $[\mathrm{M}+\mathrm{H}+\mathrm{K}]^{2+}$ ions were fragmented for each compound. It was shown that three methods of activation are complementary. For CDs, all of the fragments were formed by glycoside bonds rupture, no cleavages of residues were observed. Comparison of $\mathrm{CE}_{50}$ demonstrated that slightly higher collision energy is needed to cleave CD than the related linear maltooligosaccharide (of course, 
the corresponding ions should be considered). Though the authors claim that CID/HCD combination opens a way for deciphering of structures of complex carbohydrates "alone or in mixture", we do not share their optimism because the observed effects seem very tiny.

Thus, the choice between acyclic or cyclic structure can be supported by ESI or MALDI MS if a small amount (enough for an NMR study) of rather pure compound is isolated, but such a choice for a component in a complex mixture (when only MS alone can be used) remains problematic despite the great progress of tandem techniques during the last thirty years.

\subsection{Complexation of Cyclic OS with Other Molecules And Guests' Influence on CDs Induced Decay}

As mentioned above, most of the papers on mass spectrometry of cyclodextrins are concerned with host-guest complexes and determination of their stoichiometry, thermodynamics and chiral recognition; these aspects were thoroughly reviewed previously $[28,29]$ and are beyond the scope of this review. Nevertheless, the problem of mutual host/guest influence should be discussed. The general principle of these effects was formulated by Lebrilla and coauthors [51]. Under CID conditions, inclusion complexes can: (A) dissociate with charge retention on the host (A1) either in the guest (A2) molecule; or (B) result in cleavage of the host oligosaccharide (CD), or (C) result in cleavage of the guest molecule. CID MS of the complexes of permethylated $\beta-C D$ and native $C D$ with adenine, cytosine, guanine, thymine, and four corresponding deoxy nucleobases were studied using FT-ICR or ion trap mass spectrometers. For comparison, maltoheptaose and permethylated maltoheptaose were taken. It was shown that the preferred dissociation pathway depends on the structures of both the host OS and guest molecule. For example, cytosine assisted in fragmentation via path B inducing ring opening and intramolecular proton transfer; the presence of amino group (or, more definitely, both basic and acidic groups) in the guest molecule seemed substantial. A similar mechanism was proposed independently for fragmentation of a complex of the protonated $\beta$-CD-5-methoxytriptamine (5MTA) also studied by CID MS ${ }^{2}$ [52]. The authors have observed formation of $\beta$-CD fragments $\left[(\mathrm{Glc})_{n}+\mathrm{H}\right]^{+}, \mathrm{n}=2-5$ by activation of the protonated complex (path $B$ according to [51], see above) and proposed the relation of this fragmentation with deamination of the guest (FAB or IS, triple quadrupole, or ESI, ion trap) [52], because of proton transfer from ammonium to $\beta-C D$ was not observed previously; ammonium is assumed to be more stronger acid than protonated 5MTA. The authors proposed that deamination of $5 \mathrm{MTA}$ is the primary process and then the excited deamination product molecule (activated guest) transfer proton to the host ( $\beta-C D$ ); after that the excited host $\beta-C D$ undergoes decay (elimination of protonated guest is a parallel process). In both studies, intramolecular guest-host proton transfer was not supported in direct labeling experiment which seems really difficult to create avoiding possible side effects and uncertainties in interpretation.

It necessary to mention that not only protonated complexes of CDs were studied by tandem MS. For example, it was shown that $[\beta-\mathrm{CD}+\mathrm{PhMe}+\mathrm{Fe}]^{2+}$ complex is substantially more stable than $[\beta-\mathrm{CD}+\mathrm{PhMe}+\mathrm{H}]^{+}$; the same effect was observed by adding $\mathrm{Mg}^{2+}$ [53]. Other aromatic, low-polar molecules were studied as guests, and the stabilization effect was also observed whether real inclusion complex or electrostatic associate were formed. In this case, CID fragmentation proceeded via path A1, no CD fragments were observed. Thus, the guest-host effects are versatile (from negligible to strong) and the influence of associated cation is necessary to take into account.

\subsection{Determination of Positions of Substituents in Cyclic Oligosaccharides-General Considerations and Problems}

At present time, there are various derivatives of cyclic OSs, especially CDs prepared for different purposes. First-order MS (EI, MALDI) can obviously applied for profiling and determination of d.s. [31,37]. Since the regioisomers have the same $\mathrm{m} / \mathrm{z}$ of their ions, the application of $\mathrm{MS}^{2}$ is required. Though the differences of MS ${ }^{2}$ of regioisomeric cyclic OSs seem to be predictable, several studies were done; their results revealed some problems (see below). 
2.5.1. Tandem Mass Spectra of Monosubstituted Cyclic Oligosaccharides: The Effect of a Substituent

At first, the most used selective modification of CDs is O-6-tosylation of Glcp unit [54]. Then the OTs group may be converted to an amino group by azidation followed by reduction or substituted by a nucleophile, for example, an alkyl diamine [54]. By manipulation of protecting groups, other hydroxy groups in glucopyranosyl residues in CDs may be interchanged for amino groups. The amino groups may be subsequently modified by selective $N$-acylation or $N$-alkylation thus opening a route to various derivatives for versatile applications. In this section, we consider amino-CDs and acylamido-CDs as "substituted CDs", though they may be regarded as "mixed cyclic Oss" (containing amino sugars, see Section 2.7). The effects of amino and acetamido functional groups on ionization and fragmentation of carbohydrate units in modified $\beta$-CDs were studied in [55]. Monosubstituted 3-NH$-\mathrm{N}_{2}-\beta_{-} \mathrm{CD} 7$ and 3-NHAc- $\beta$-CD 8 (Figure 7) were taken for the tandem MS (LID MALDI and ESI MS ${ }^{2}$ ) study. Note that a synthesis of the derivatives resulted in inversion of the C-2 and C-3 configurations, so the glucopyranose residue transformed into 3-amino-3-deoxyaltropyranose unit (designated here as HexN), however, one can believe that the change of stereochemistry had an apparently negligible effect on tandem mass spectra. For 3-NH$-\beta-C D$, both $[\mathrm{M}+\mathrm{H}]^{+}$and $[\mathrm{M}+\mathrm{Na}]^{+}$were observed in MALDI and ESI MS. LID and CID of the protonated molecule resulted in similar secondary-order mass spectra with predominant formation of aminohexose-containing fragments, so, a proton is definitely localized on the amino group and the first cleavage of glycosidic bond occurs near the HexN residue (Figure 8b). For LID MALDI TOF/TOF MS of $[\mathrm{M}+\mathrm{Na}]^{+}$, HexN-containing fragments were only $[\mathrm{HexN}+\mathrm{Glc}$ $+\mathrm{Na}]^{+}$and $\left[\mathrm{HexN}+\mathrm{Glc}_{2}+\mathrm{Na}\right]^{+}$along with $\left[\mathrm{Glc}_{\mathrm{n}}+\mathrm{Na}\right]^{+}, \mathrm{n}=2$ and 3, no aminosugar-containing fragments were observed for $\mathrm{n}=4,5$, and 6 (Figure 8a). One can assume that $\mathrm{Na}^{+}$ion coordinates both with Glc and HexN residues thus results in almost random cleavage of glycosidic bonds. In contrast, in LID MALDI MS of $[\mathrm{M}+\mathrm{Na}]^{+}$for 3-NHAc- $\beta-\mathrm{CD}$, HexNAc-containing fragments are at least twice more abundant than corresponding $\left[\mathrm{Glc}_{n}+\mathrm{Na}\right]^{+}$ions (Figure 9). The authors suggested that $\mathrm{Na}^{+}$is prone to coordinate with HexNAc residue stronger than with underivatized Glc unit [55].
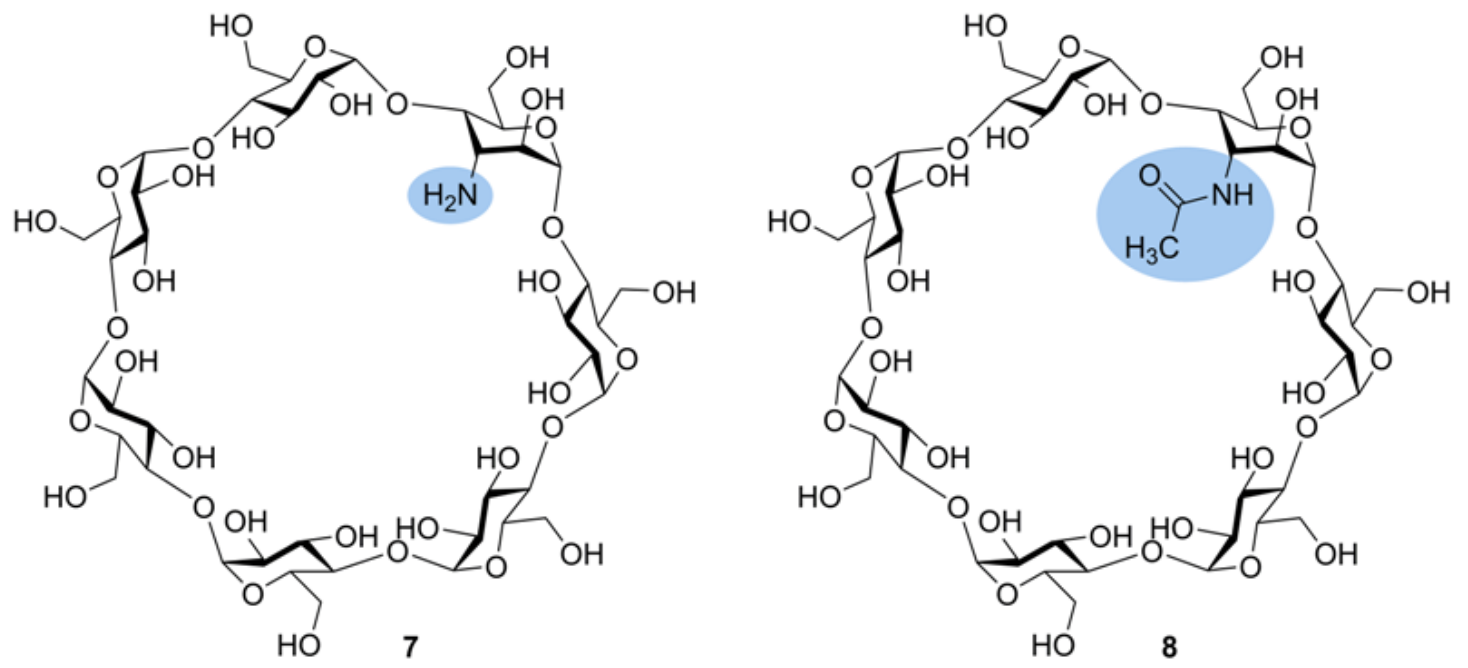

Figure 7. Structural formulas of monosubstituted 3-amino $\beta$-CD 7 and 3-acetamido $\beta$-CD 8 [55]. Nitrogen-containing functional groups are highlighted. 
a
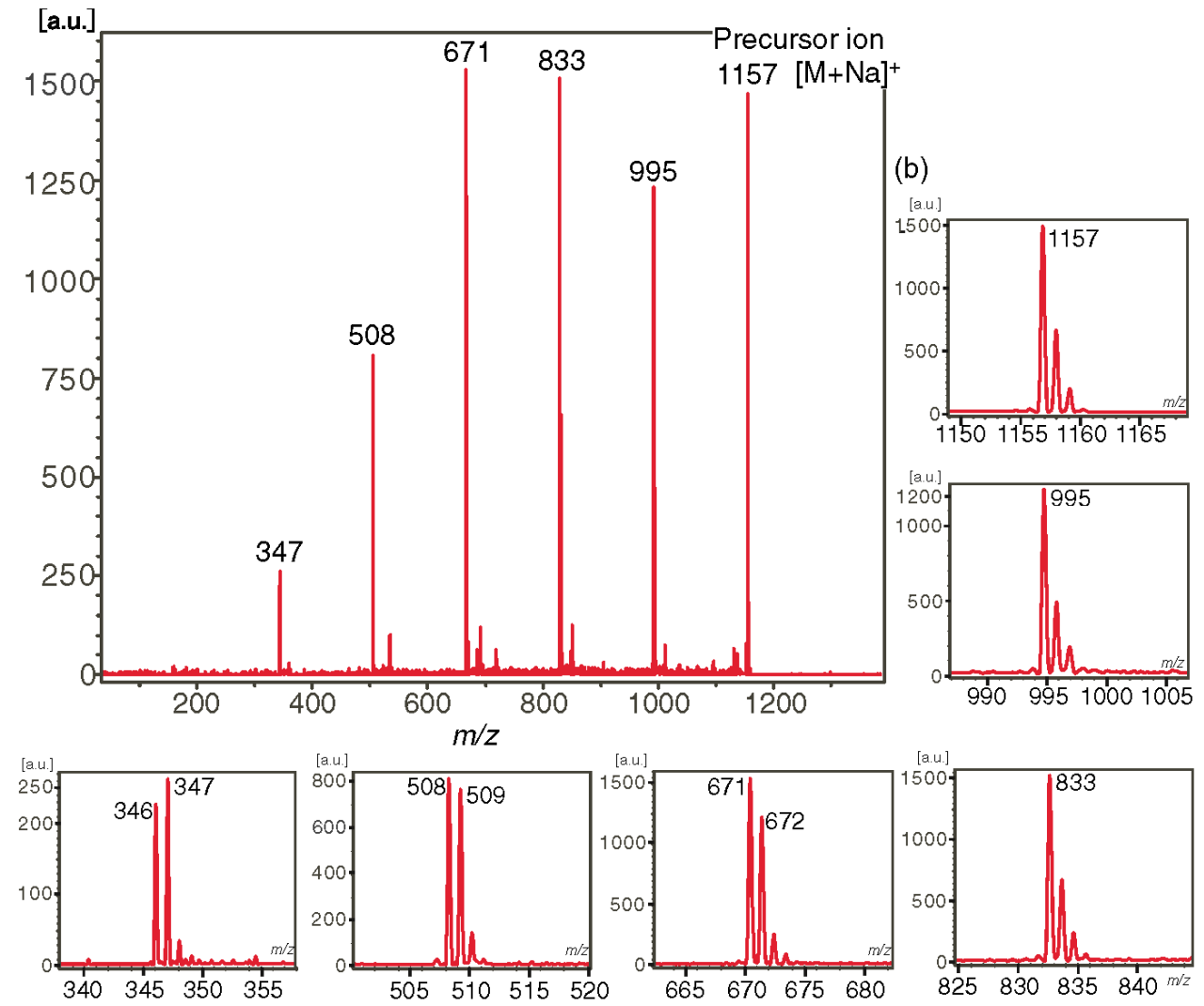

b

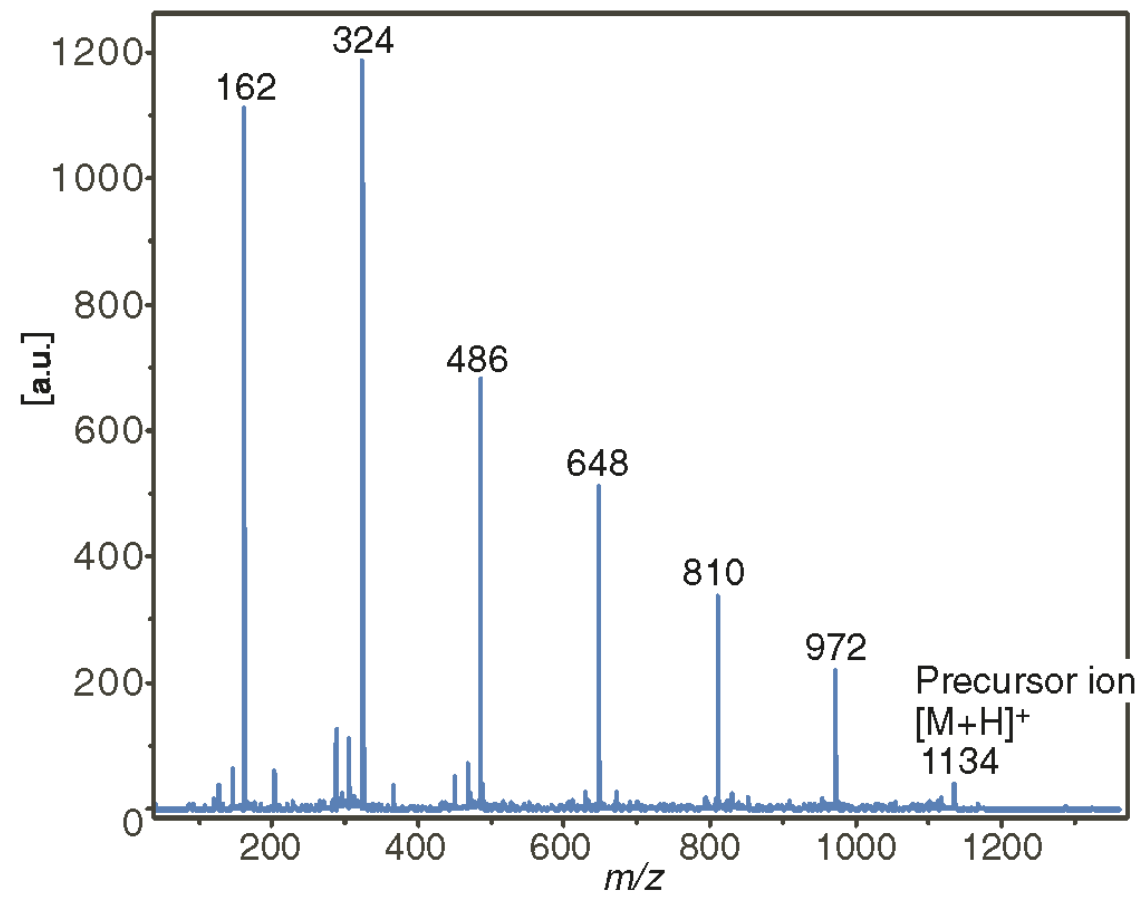

Figure 8. LID MALDI TOF/TOF MS of ions generated from 7. (a) $\mathrm{MS}^{2}$ of $[\mathrm{M}+\mathrm{Na}]^{+}$ion, extensions of isotopic clusters are presented in insets; $(\mathbf{b}) \mathrm{MS}^{2}$ of $[\mathrm{M}+\mathrm{H}]^{+}$ion (reproduced from [55], Open Access material under the Creative Commons license.). 


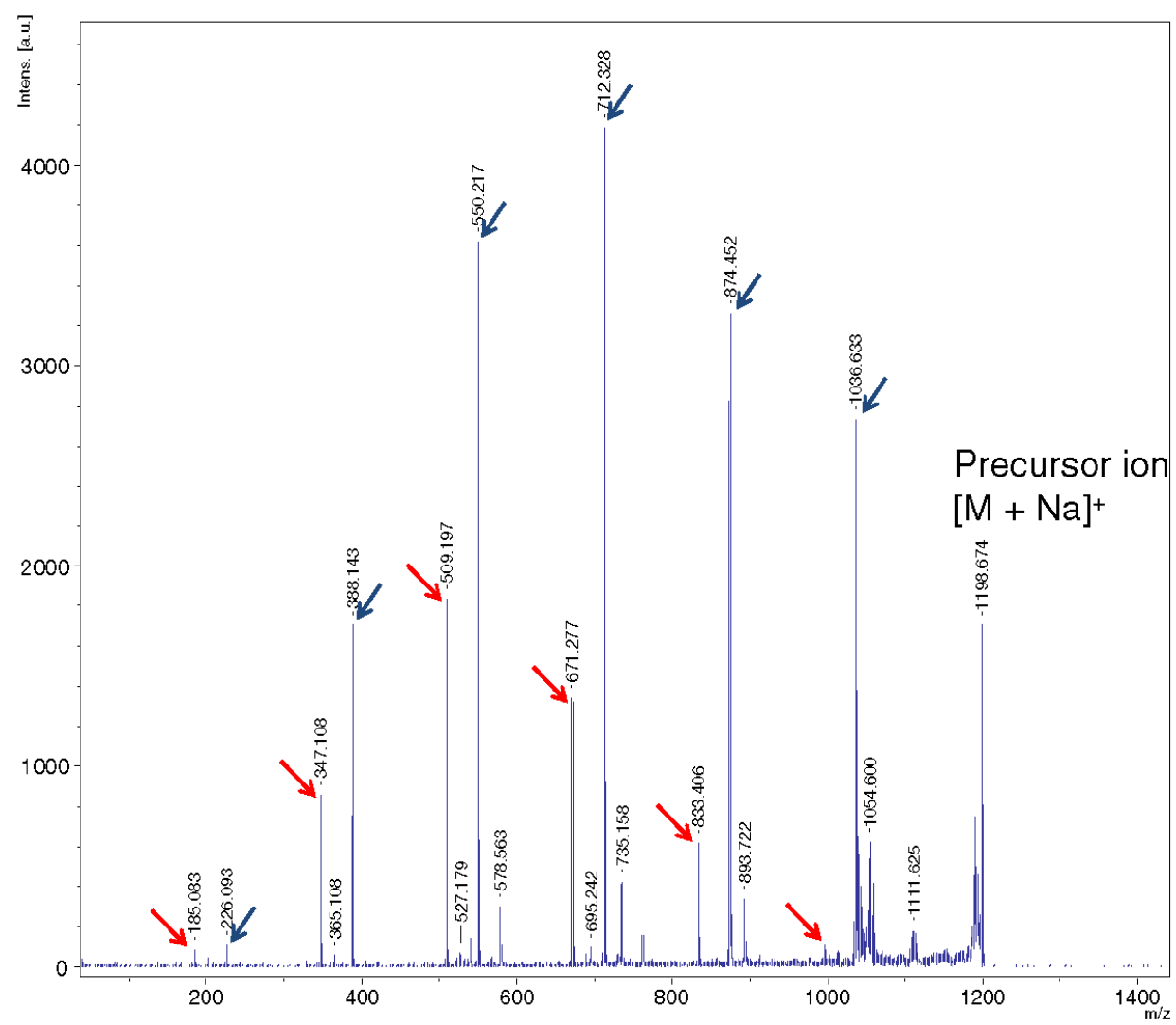

Figure 9. LID MALDI TOF/TOF MS of the $[\mathrm{M}+\mathrm{Na}]^{+}$ion generated from 7. Peaks of NHAc-containing ions are marked by blue arrows, and red arrows show peaks of ions with no nitrogen (reproduced from [55], Open Access material under the Creative Commons license).

\subsubsection{Tandem Mass Spectra of Disubstituted CDs: Effect of Positions of Substituents}

The influence of the positions of regioisomeric, disubstituted $\beta$-cyclodextrins on their ESI MS $^{2}$ mass spectra was studied in [15] for two triplets of substituted $\beta$-cyclodextrins: bis(6-bis(2-picolyl)glycylamido)-6-deoxy- $\beta$-CD (9a-11a) and bis(6-O-tosyl)- $\beta$-CD (12-14). One can assume that mass spectra of decay for regioisomers of modified CDs (as well as for any cyclic oligosaccharides) may differ from each other since a double rupture of glycosidic bonds can result in different combinations of primarily bonded units. A critical consideration of this approach may be formulated in two questions:

(1) Are the bonds between substituents and the carbohydrate units strong enough in comparison to glycosidic bonds, and

(2) Do transitions of substituents between carbohydrate residues (i.e., rearrangements) take place?

The negative answer on the first question and/or positive on the second one makes mass spectrometric structural assignment of these compounds impossible. A study of two series [15] (see above) has shown that both variants are possible. Thus, for regioisomers with bispicolylamide substituents ( $A B$ has adjacent substituted units, 9a, in $A C$, they are separated with one and four unsubstituted units, 10a, and in AD, 11a, substituted units are separated with two and three unsubstituted units, Figure 10) fragmentation of glycosidic bonds is predominant and transition of these substituents between units does not observed thus resulting in characteristic $\mathrm{MS}^{2}$ for all three $[\mathrm{M}+\mathrm{H}]^{+}$ions (these peak series are basically arisen due to a cleavage of glycosidic bonds, Figure 11). For $\mathrm{AB}$, the fragment consisting of two substituted units is present $(\mathrm{m} / \mathrm{z} 801)$, but it is absent in $\mathrm{MC}^{2}$ of $\mathrm{AD}$ and AC. The fragment consisting of two substituted and one unsubstituted unit $(\mathrm{m} / \mathrm{z} 963)$ is absent ${ }_{\mathrm{BMS}}{ }^{2}$ of $\mathrm{AD}$. The peak of the ion resulting from elimination of one substituent $(\mathrm{m} / \mathrm{z} 1732.5)$ is present in 
$\mathrm{MS}^{2}$ of all three regioisomers, nevertheless, this pathway does not dominate. For bis-6-O-tosylates, the fragmentation differs drastically: CID MS ${ }^{2}$ of $[\mathrm{M}+\mathrm{H}]^{+}$for ditosylates $\mathrm{AC}$ and $\mathrm{AD}$ are practically the same, and for $\mathrm{AB}$, the same pattern of ions was observed though peaks assigned to ditosylated maltose $(\mathrm{m} / \mathrm{z} 633)$ and ditosylated maltotriose $(\mathrm{m} / \mathrm{z} 795)$ have higher relative abundances than those of $\mathrm{AC}$ and $\mathrm{AD}(\mathrm{m} / \mathrm{z} 479,100 \%$ is assigned to monotosylated maltose, Figure 12). Apparently, O-tosyl group can migrate between glucosyl residues in cyclodextrin under CID. Unfortunately, it was not

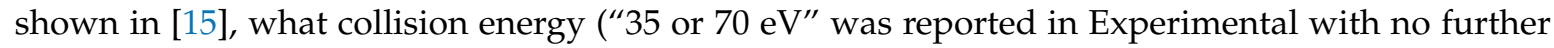
reference) was definitely applied in each case: that is likely to be critical for the result of tandem experiment. Moreover, there are no tandem spectra for $[\mathrm{M}+\mathrm{Na}]^{+}$tosylates: such an investigation may be promising because it is generally accepted that the alkali metal-associated ions of OSs do not undergo rearrangements [56,57].

It is difficult to discuss a similar early study [36] because the data obtained there look unreliable, at least, in part. Because a monoquadrupole, low resolution instrument was available, unselective CID was achieved by applying an elevated cone voltage (190 V). Nevertheless, CID pseudo-MS ${ }^{2}$ of $[\mathrm{M}+\mathrm{Na}]^{+}$of three $6,6^{\prime}$-diamino $\beta$-CDs $\mathbf{9 b}-\mathbf{1 1 b}$ seem to be conclusive. Really, in the range of sodiated three-residues ion ( $m / z 507$ to $m / z 511$, Figure 13) the differences between $A B, A C$, and AD isomers were clear despite of incomplete resolution of the peaks: the absence $m / z 507$ peak for AD, $m / z 509$ was the highest for $\mathrm{AB}$, and for $\mathrm{AC}$, comparable intensities of $m / z 508$ and $m / z 509$ were observed (the hypothesis of random cleavage of glycosidic bonds in $[\mathrm{M}+\mathrm{Na}]^{+}$was later proved for a monoamino derivative [55], see above). Three isomeric tosylates and two isomeric mesitylates were studied without independent determination of their structures hence the assignments in the second part of the study cannot be considered as reliable.
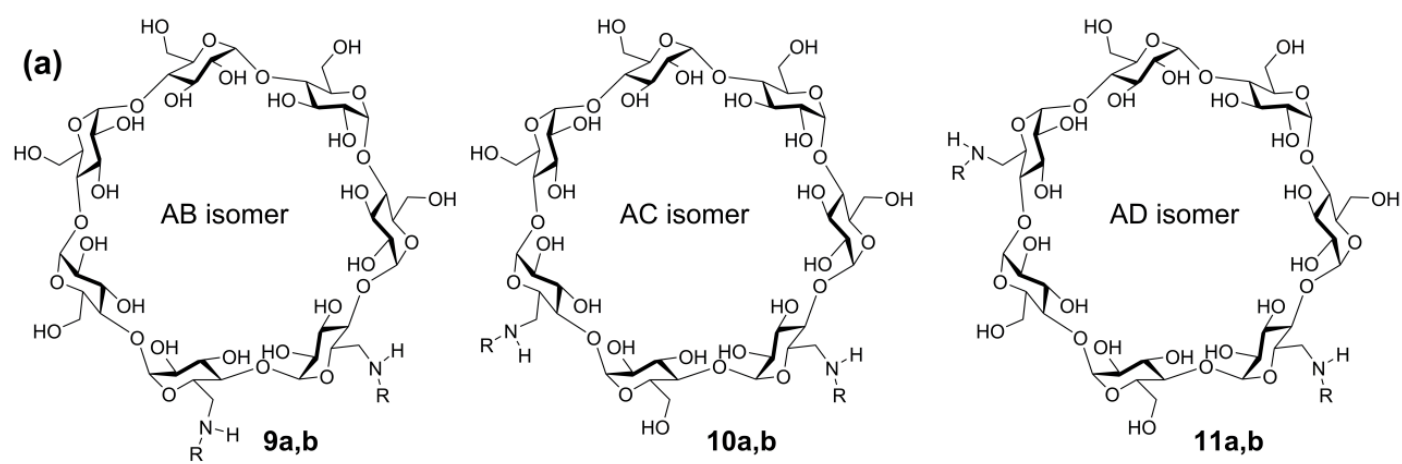

a $R=$ bis (picolyl)glycyl [15] b $\mathrm{R}=\mathrm{H}[35]$
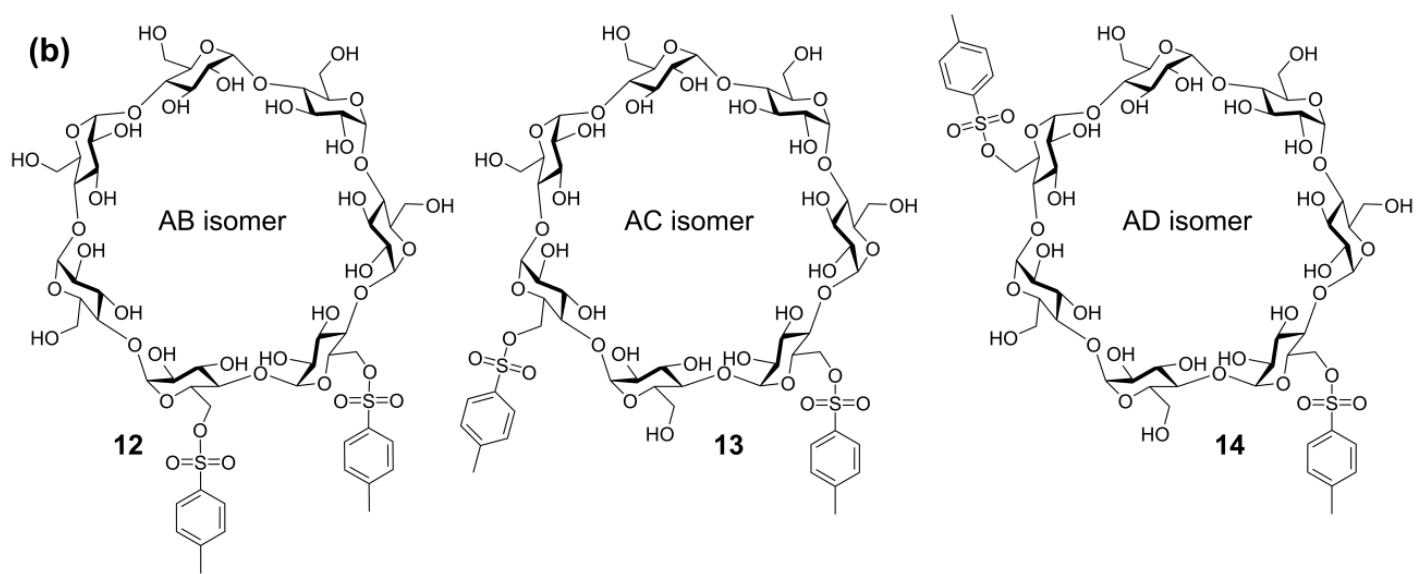

Figure 10. Structures of disubstituted $\beta$-cyclodextrins AB, AC, and AD (a) di(bis(picolyl)glycyl)amides 9a-11a, diamines 9b-11b; (b) di-O-tosylates 12-14 [15,36]). (Reproduced with changes from [36] with permission of Springer Nature). 
(a) $\mathrm{AB}$ isomer 9a $\quad[\mathrm{M}-5 \mathrm{Glu}]^{+} \quad[\mathrm{M}-4 \mathrm{Glu}]^{+} \quad[\mathrm{M}-3 \mathrm{Glu}]^{+} \quad[\mathrm{M}-2 \mathrm{Glu}]^{+} \quad[\mathrm{M}-\mathrm{Glu}]^{+}$

$*$

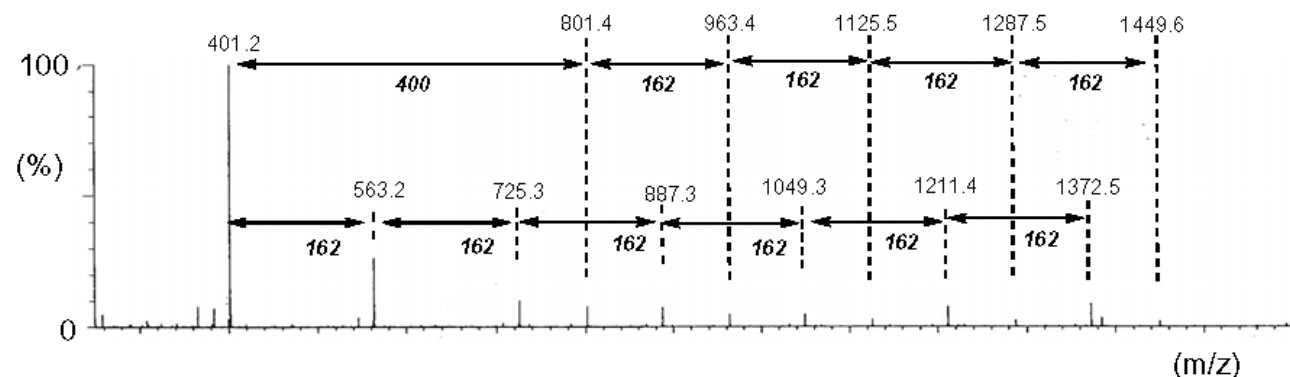

(b) AC isomer 10a

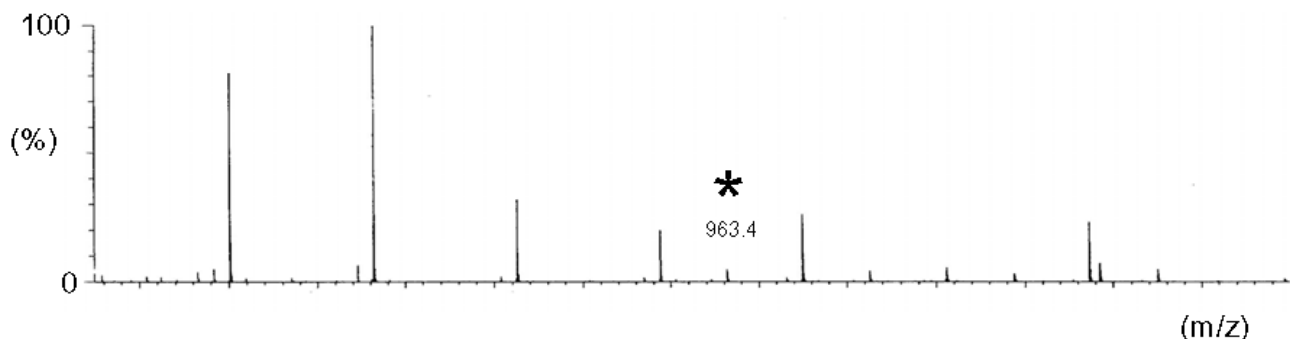

(c) AD isomer 11a

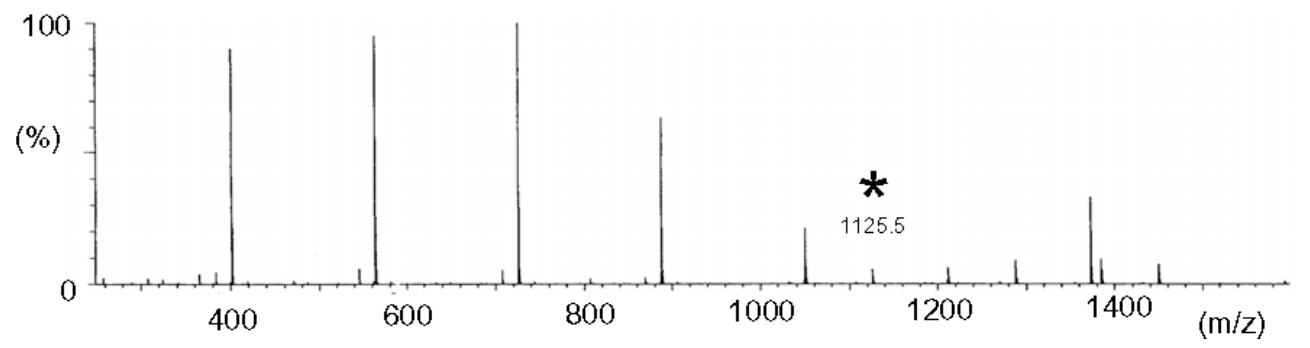

Figure 11. ESI CID MS ${ }^{2}$ of $[\mathrm{M}+\mathrm{H}]^{+}\left(m / z\right.$ 1612.5) of three regioisomes of di-6, $6^{\prime}-N, N^{\prime}$-(bis(picolyl)glycylamido)- $\beta$-CDs 9a-11a (a-c). The characteristic peaks of fragment ions are marked with asterisks (reproduced from [15] with permission of SAGE Publications Ltd.). 
12, AB-isomer

13, AC-isomer
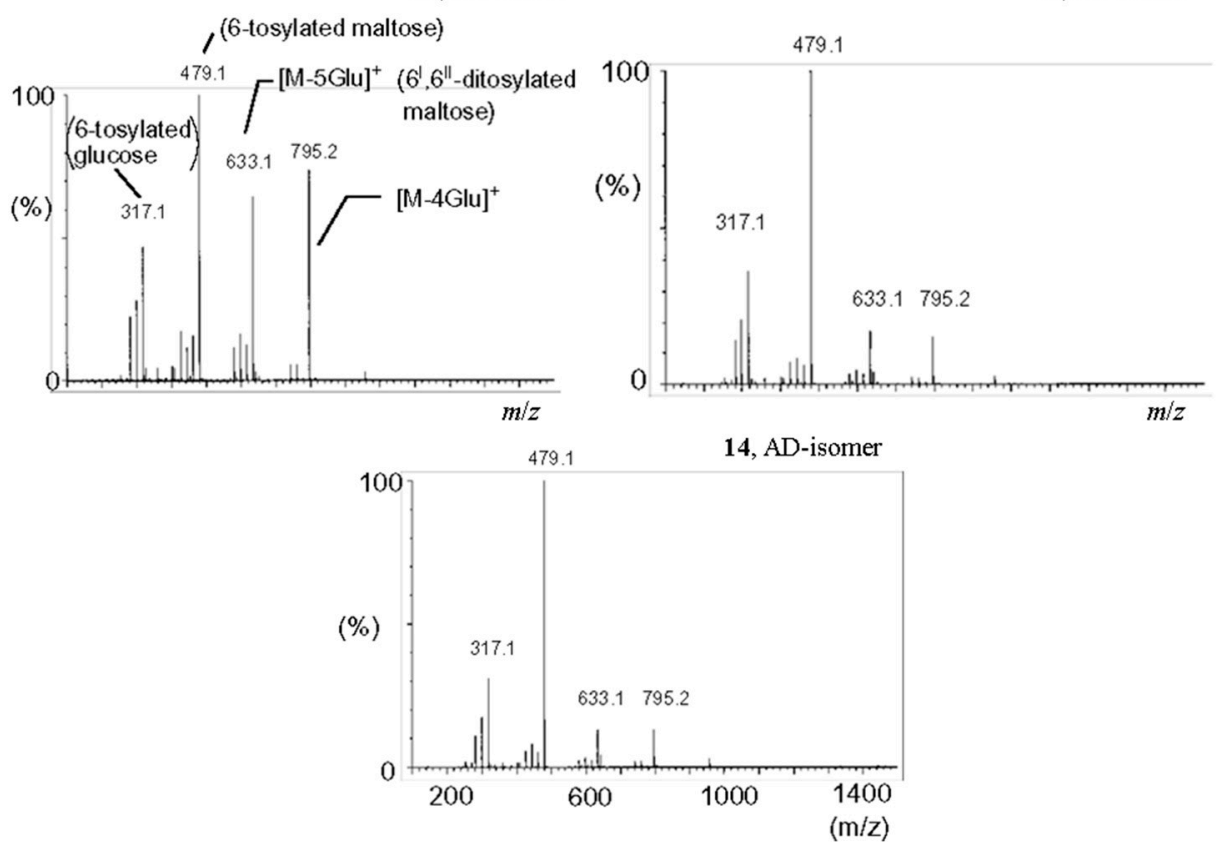

Figure 12. ESI CID MS ${ }^{2}$ of $[\mathrm{M}+\mathrm{H}]^{+}\left(m / z\right.$ 1443.4) of three regioisomes of di-6,6'-O, $\mathrm{O}^{\prime}$-tosyl- $\beta$-CDs 9a-11a (reproduced from [15] with permission of SAGE Publications Ltd.).
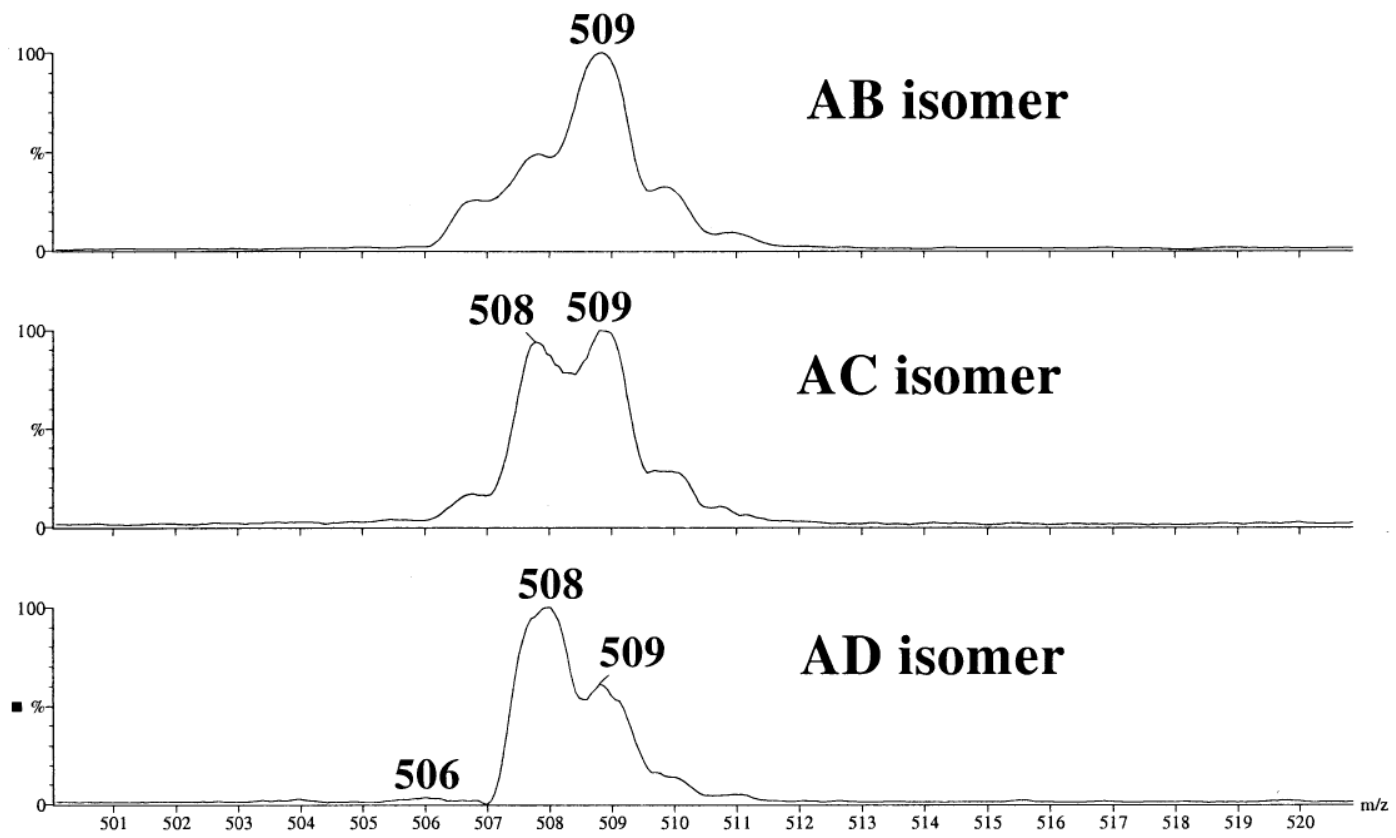

Figure 13. A characteristic part of pseudo-MS ${ }^{2}$ of $[\mathrm{M}+\mathrm{Na}]^{+}$of three regioisomeric $6,6^{\prime}$-diamino $\beta$-CDs (9b-11b) (reproduced from [36] with permission of Springer Nature).

\subsection{Tandem Mass Spectra of Complex And Highly Substituted CD Derivatives}

2.6.1. Tandem Mass Spectra of CD Derivatives Possessing Succinyl-Spacered Dicationic Substituent (Gemini Surfactants)

Cyclic OSs, especially CDs, are used as starting compounds for the construction of complex organic and hybrid molecular systems. For example, CDs are applied for preparation of drug delivery agents in which a CD core is tethered by ether or ester bonds with linkers bearing side ionogenic 
groups. A scheme of CID fragmentation of a series of surfactants based on 6-O- or 6- $\mathrm{N}$-monoacylated $\beta$-CD (Figure 14) was presented [58]. The study was performed using an ESI-equipped hybrid triple quadrupole-linear ion trap (LIT) instrument. For all of four $\beta-C D$ dication derivatives, abundant $\mathrm{M}^{2+}$ ions were observed. CID of $\mathrm{M}^{2+}$ resulted in the loss of one $\mathrm{N}$-alkyl (in a form of alkene) followed by $\mathrm{NHMe}_{2}$ loss. The $\left[\mathrm{M}-\left(\mathrm{NMe}_{2} \mathrm{R}\right)\right]^{2+}$ ion eliminated one singly charged Glc residue from $\beta-\mathrm{CD}$ thus opened the cycle. Two pathways of further fragmentation were realized. Path 1: Glc neutrals are sequentially lost. Path 2: the second alkyl and $\mathrm{NHMe}_{2}$ were lost followed by sequential loss of Glc units. Cleavage of the carbohydrate residues also occurred simultaneously. This complicated scheme of thoroughly investigated fragmentation was supported using $\mathrm{MS}^{3}$ to reveal fragment ion transitions (and for one compound, deuterium labeling of alkyls were applied). All studied compounds had similar fragmentations, no drastic differences between $\mathrm{O}$ - and $\mathrm{N}$-succinates were reported.

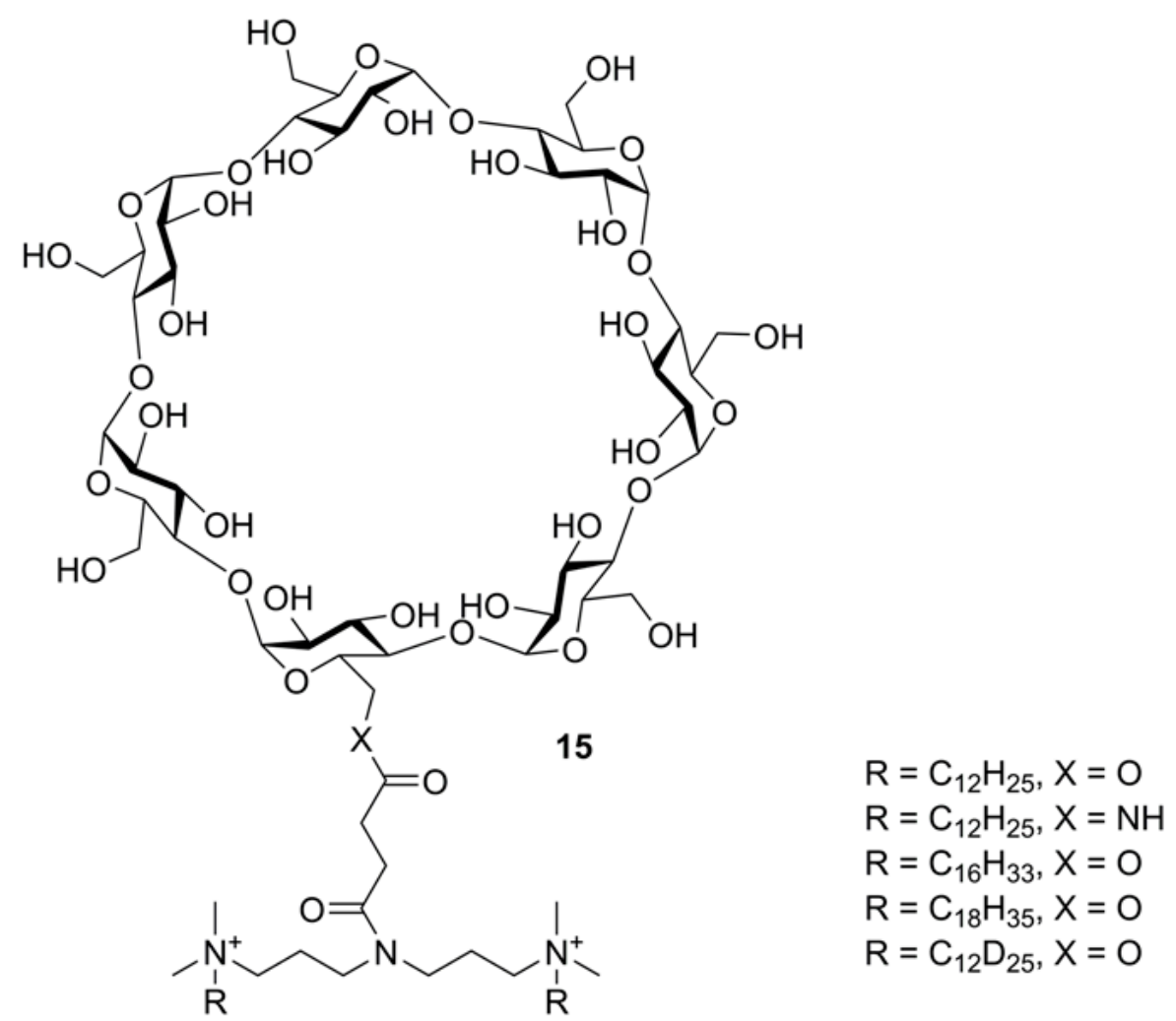

Figure 14. The structures of $\beta$-CD-based surfactants (reproduced from [58] with permission of Wiley).

\subsubsection{Tandem Mass Spectra of Polysubstituted (Multiply Acylated) CD Derivatives}

For the last two decades, CDs were used as scaffolds for star polymers, the best known being the oligolactide-tethered CDs produced by ring-opening polymerization of lactide (the cyclic dimer of lactic acid) initiated by CD, where oligolactide forms a chain attached to the CD [59-64]. To optimize this synthesis and to achieve high d.s., it is necessary to control the polymerization; both NMR and MS are applied (sometimes along with other methods, e.g., IR spectroscopy and electron microscopy [64]). The most often used MS procedure is MALDI MS profiling [59,60,62,63]. In the recent work of Peptu and Mosnaček collaboration [63], a simple formula was reported for MALDI profiling of a fraction of $\beta$-CD-LA:

$$
m / z=1134(\beta-C D)+\mathrm{n} \times 144(\mathrm{LA})+39(\mathrm{~K})
$$

where $\mathrm{n}$ is d.s., LA means an increment of the residue of lactide (144 Da), $\mathrm{K}$ means that potassium adducts are mainly formed, however, adducts with $\mathrm{Na}^{+}$were also identified. It was stressed that "LC with on-line ESI MS detection has problems with the analysis of polymer species related to formation of multicharged ions thus creating difficulties in spectra interpretation, especially in the case 
of polydisperse oligomer mixtures" [63]. To solve this problem, Peptu et al. studied the possibility of using tandem mass spectra for the structure elucidation of CD esters $[65,66]$. Totally acetylated $\beta-C D$ (TABCD), $\beta-C D$ randomly acylated with butyrolactone (HBCD) [65], and $\beta-C D$ partially substituted with oligolactide chains [66] were used (Figure 15). Tandem mass spectra were acquired with a QqTOF instrument, elevated cone voltage $(200 \mathrm{~V})$ and activation in the collision cell were applied simultaneously. The accuracy of the $\mathrm{m} / \mathrm{z}$ measurements may be considered as fair, the integer monoisotopic masses have good agreement with those calculated. In the $\mathrm{MS}^{1}$ of TABCD, $[\mathrm{M}+\mathrm{H}]^{+}$and $[\mathrm{M}+\mathrm{Na}]^{+}$were present, and their $\mathrm{MS}^{2}$ spectra differed drastically. For $\mathrm{MS}^{2}$ of $[\mathrm{M}+\mathrm{H}]^{+}$(c.e. $20 \mathrm{eV}$ ), stepwise losses of HOAc and Glc units were observed: after elimination of four HOAc molecules, elimination of one Glc unit occurred until all co-monomer units were depleted. This process was readily illustrated in the table of all possible $m / z$ values, where really observed $m / z$ ones were highlighted forming a kind of ladder. For $\mathrm{MS}^{2}$ of $[\mathrm{M}+\mathrm{Na}]^{+}$(c.e. $120 \mathrm{eV}$ ), only consecutive losses of four molecules of HOAc (accompanied in lesser extent, by $\mathrm{C}_{2} \mathrm{H}_{2} \mathrm{O}$ losses) were observed. In a small $\mathrm{m} / \mathrm{z}$ range, abundant peaks corresponding to acetylated Glc unit fragments were present. As it was demonstrated previously by NMR and MS [67], the applied sample of HBCD contained $\beta-C D$ esterified by single hydroxybutyryl residues (mainly at O-3), their numbers varied from one to seven. The aim was to prove by $\mathrm{MS}^{2}$ alone that there were no oligomeric hydroxybutyryl substituents (which may occur due to esterification of a hydroxyl to give a hydroxybutyryl moiety). Abundant $[\mathrm{M}+\mathrm{Na}]^{+}$ions along with quite visible $[\mathrm{M}+\mathrm{H}]^{+}$ones were observed for each component in ESI MS. For $\mathrm{MS}^{2}$ of $[\mathrm{M}+\mathrm{H}]^{+}$of $5 \mathrm{HB}$-substituted $\beta-C D$ (c.e. $15 \mathrm{eV}$ ), a subsequent loss of Glc units (162 Da) accompanied by losses of HB substituents (104 Da) and their anhydro forms (86 Da) occurred. A similar "ladder", but with smaller steps was pictured in the table created analogously to $\mathrm{MS}^{2}$ of TABCD. $\mathrm{MS}^{2}$ of the $[\mathrm{M}+\mathrm{Na}]^{+}$ion (c.e. $110 \mathrm{eV}$ ) contained peaks corresponding to different fragmentation pathways. Ions $\mathrm{m} / \mathrm{z} 1483$ and $\mathrm{m} / \mathrm{z} 1379$ are formed due to losses of one and two HB molecules. The ion $m / z 1425$ resulted in loss of one Glc unit, and the ion $m / z 1339$ was formed due to (Glc-HB) loss (104+86 Da). Because of the ion $m / z 1397$ (loss of $\mathrm{HB}_{2}, 104+86 \mathrm{Da}$ ) was not observed, one can conclude that there were likely no di-HB substituent attached to $\beta$-CD. The origin of the quite abundant $m / z 1543$ ion (loss of $44 \mathrm{Da}$ ) was not definitely explained by the authors; due to low resolution, it was impossible to find out what neutral $\left(\mathrm{C}_{2} \mathrm{H}_{4} \mathrm{O}\right.$ or $\mathrm{CO}_{2}$ ) was eliminated. The above fragmentation pathways classified by Peptu et al. are presented in Figure 15. Note, that this is an ad hoc description, and the letters A, B, and C have different meaning from that of Domon-Costello nomenclature [40].

Recently, a mixture of derivatized $\beta$-CDs partially substituted with oligolactide chains was studied by GPC, NMR, and MS [66]. From the NMR spectra the authors concluded that oligolactides were attached as multiple short chains to different $\mathrm{OH}$ groups of the CD molecules. From MALDI MS profiling, an average of 15.6 lactate units per $\beta-C D$ were calculated. Tandem MS (ESI MS ${ }^{2}$ and MALDI LID) were thoroughly described for the $\left[\beta-\mathrm{CD}-\mathrm{LA}_{4}+\mathrm{Na}\right]^{+}$ion with total assignment of composition of fragment ions. In contrast to the above examples, multiply repeated units in substituents capable of fragmentation were definitely present, so three other pathways were observed designated as G (loss of substituted Glc unit) and E1 and E2 (fragmentation of side lactide chains), Figure 15, bottom. As expected, the most intense peaks corresponded to fragments containing an even number of lactate units. Minor peaks with an odd number of lactate units were also present because transesterification is possible during ring-opening, CD-induced polymerization of lactide. The same regularities were found for $\mathrm{K}^{+}$and $\mathrm{Li}^{+}$adducts; heavier ions having more lactate units gave homologous fragmentation patterns.

Several related studies on multiply acylated CDs were reported. Profiling of HBCD mixture (see above) was done successfully using HPLC-ESI-MS along with NMR of separated fractions [67]. A similar study of modified, amphiphilic CD mixtures was done with HPLC-MS [68]. Selectively $O$-benzylated (with only two free OH groups) $\beta-C D$ was transferred to a homologous mixture of oligopolylactides, which was characterized by MALDI TOF profiling along with NMR spectrometry [69]. 

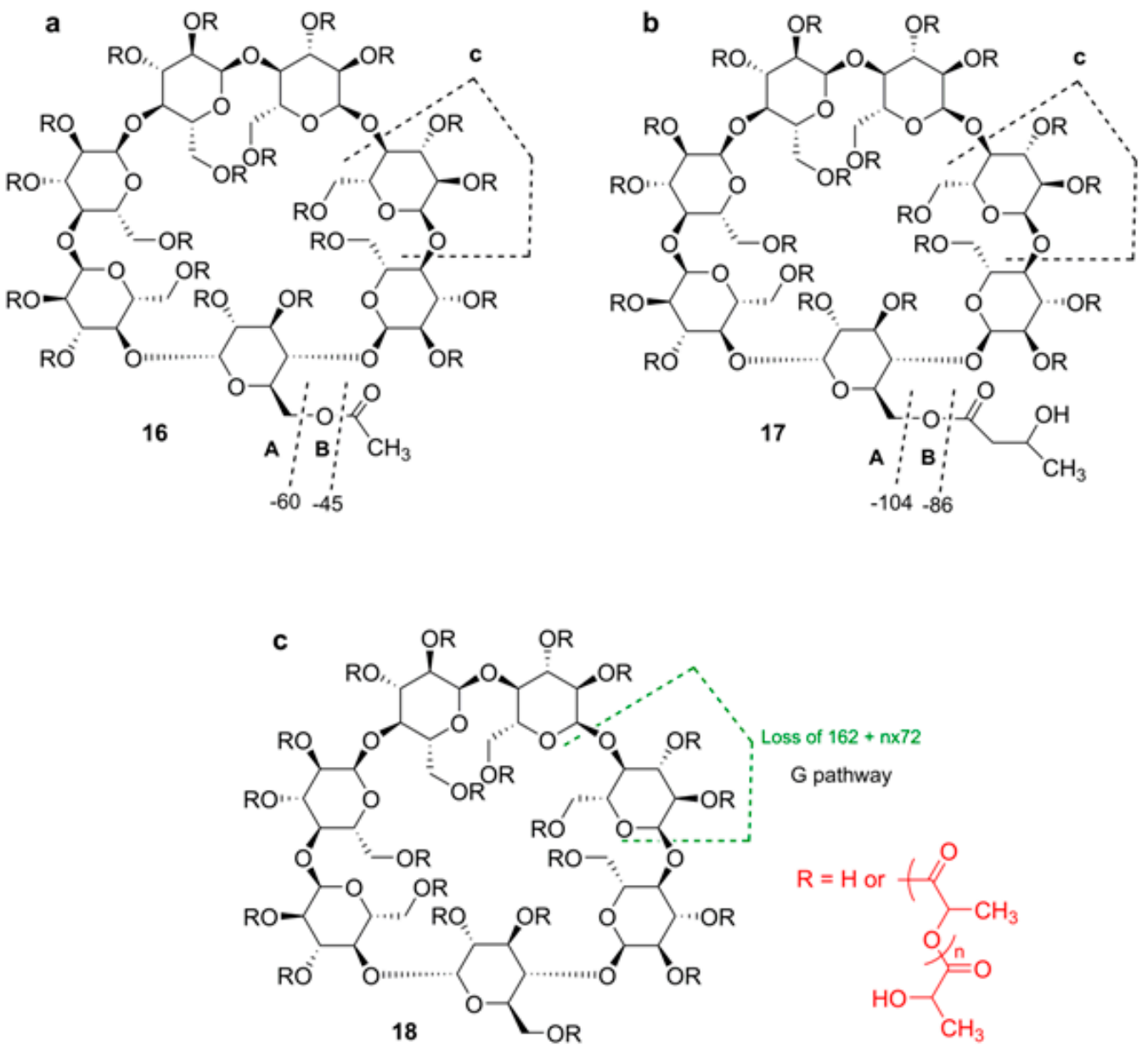

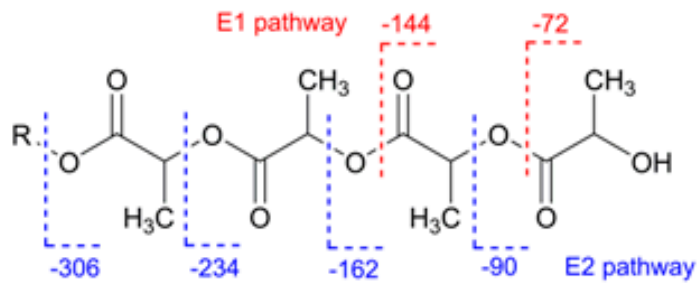

Figure 15. Fragmentation of acylated $\beta$-CDs according to Peptu et al. (a) totally acetylated, TABCD [65]; (b) randomly 3-hydroxybutyrated, HBCD [65]; (c) oligolactate [66]. (Open Access material under the Creative Commons license).

One can mention that the aim of these mass spectrometric studies $[65,66]$ was deliberately restricted: only stoichiometry of CDs derivatives was correlated with $\mathrm{MS}^{2}$ profiles, not positions of substituents, so the problem of acyl migration was beyond the scope. Despite the complexity of the NMR spectra of derivatives of CDs, this method including 2D NMR procedures remains the gold standard in structure determination of substituted CDs.

\subsection{Tandem Mass Spectra of Cycloaminooligosaccharides and Mixed Cyclooligosaccharides}

\subsubsection{General Information}

Recently, Chizhov et al. reported extensive studies concerning high resolution tandem mass spectrometry (ESI QqTOF) of cyclooligo- $\beta-(1 \rightarrow 6)$-D-glucosamines, cyclooligo- $\beta$-( $1 \rightarrow 6)$-D- $N$-acetylglucosamines (from two to seven GlcN or GlcNAc residues, respectively, 19a,b-24a, b, Figure 16) [70],

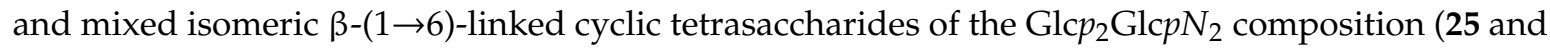


26, Figure 17) [71]. Synthetic details for the preparation, structural and conformational analysis of cyclo- $\beta$-(1 $\rightarrow 6)$-D-glucosamines 19a,b-24a,b were described in [72-74].

These compounds were used as versatile scaffolds in the design of oligodentate blockers of oligomeric bacterial lectins $[75,76]$ and building blocks for creation of artificial ion channels $[77,78]$.

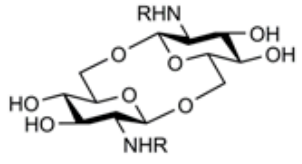

19a,b

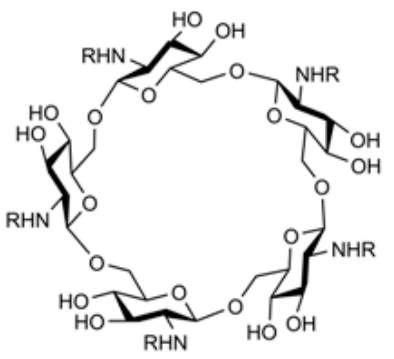

22a,b

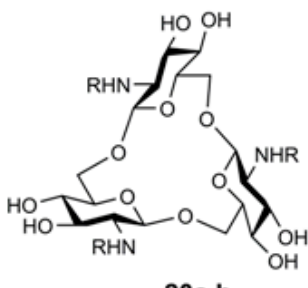

20a,b

a $\mathrm{R}=\mathrm{H}$

b $\mathrm{R}=\mathrm{Ac}$

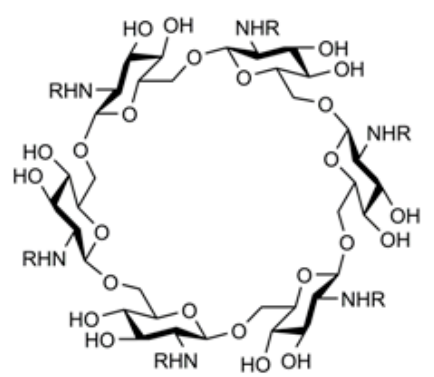

23a,b
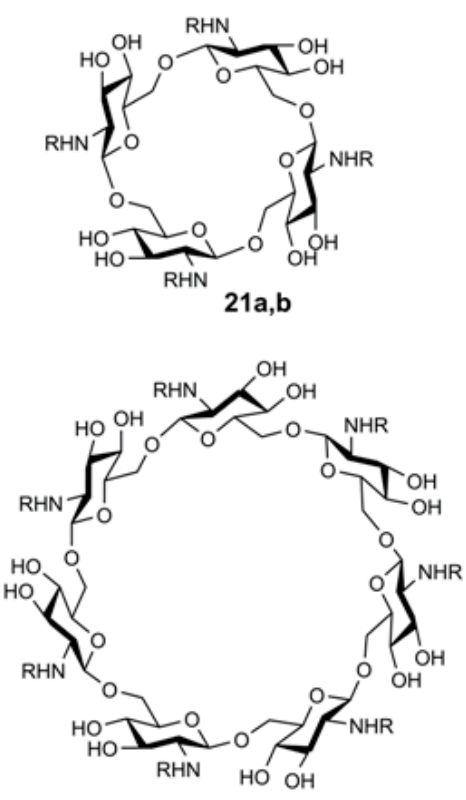

24a,b

Figure 16. Structural formulas of cyclooligo- $\beta-(1 \rightarrow 6)$-D-glucosamines $19 a-24 a$ and cyclooligo- $\beta-(1 \rightarrow 6)-$ D-N-acetylglucosamines 19b-24b [70,72-74] (reproduced from [70] with permission of Springer Nature).

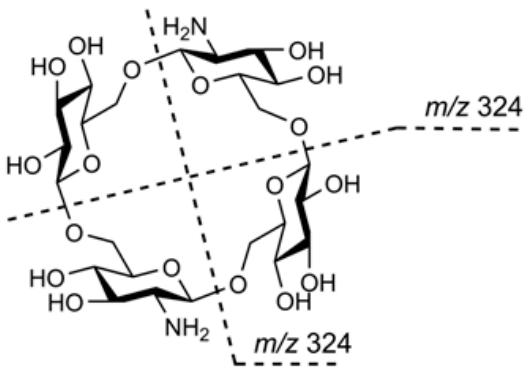

25

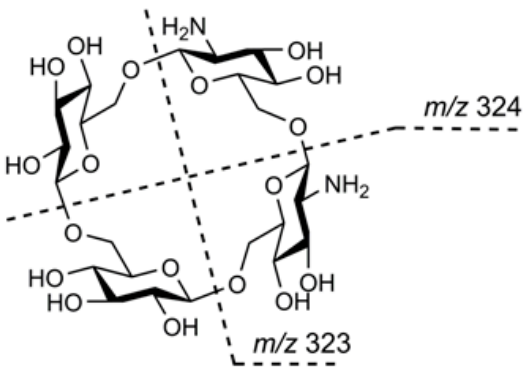

26

Figure 17. Structural formulas of cyclobis- $(1 \rightarrow 6)-(\beta$-D-glucopyranosyl)-(1 $\rightarrow 6)-(2$-amino-2-deoxy- $\beta$-Dglucopyranosyl) 25 and cyclo-(1 $\rightarrow 6)$-(2-amino-2-deoxy- $\beta$-D-glucopyranosyl)-( $1 \rightarrow 6)$-(2-amino-2-deoxy- $\beta$ D-glucopyranosyl)-( $1 \rightarrow 6)-(\beta$-D-glucopyranosyl)-( $1 \rightarrow 6)-(\beta$-D-glucopyranosyl) 26 .

First-order, electrospray ionization (ESI) mass spectra of compounds 19a,b-24a,b, 25 and 26 have prominent peaks of ions $[\mathrm{M}+\mathrm{H}]^{+},[\mathrm{M}+2 \mathrm{H}]^{2+},[\mathrm{M}+\mathrm{Na}]^{+},[\mathrm{M}+\mathrm{K}]^{+}$, and a moderate peak of an $[\mathrm{M}-\mathrm{H}]^{-}$anion. The ions $\left[\mathrm{M}+\mathrm{NH}_{4}\right]^{+}$are formed only for cyclic $\mathrm{N}$-acetylglucosamines $\mathbf{1 9 b}-\mathbf{2 4 b}$, not for cyclooligoglucosamines 19a-24a.

\subsubsection{Tandem Mass Spectra of Cycloaminooligosaccharides}

In the positive ion mode ESI CID MS ${ }^{2}$ spectra of cyclooligo- $\beta-(1 \rightarrow 6)$-D-glucosamines 19a-24a and cyclooligo- $\beta$-( $1 \rightarrow 6)$-D- $N$-acetylglucosamines $\mathbf{1 9} \mathbf{b}-\mathbf{2 4} \mathbf{b}$, cleavages of the glycosidic bonds were the principal processes, they are accompanied by eliminations of molecules of water (and ammonia for cyclooligo- $\beta$-( $1 \rightarrow 6)$-D-glucosamines) [70]. For example, protonation of the cyclic dimer of glucosamine 19a produced the $[\mathrm{M}+\mathrm{H}]^{+}$and $[\mathrm{M}+2 \mathrm{H}]^{2+}$ ions. The main fragment of activation (c.e. $25 \mathrm{eV}$ ) of the 
singly charged ion, $[\mathrm{GlcN}+\mathrm{H}]^{+}$(Figure 18) had the same $\mathrm{m} / \mathrm{z} 162.0760$ that the doubly charged ion, but it differed from that one by positions of isotopic peaks. This fragment arose by cleavage of two glycosidic bonds. Peaks with lower intensities resulted in further fragmentation of the glucosamine residue with a loss of one or two molecules of water, [GlcN $\left.+\mathrm{H}-\mathrm{H}_{2} \mathrm{O}\right]^{+}$and $\left[\mathrm{GlcN}+\mathrm{H}-2 \mathrm{H}_{2} \mathrm{O}\right]^{+}$, respectively. The protonated molecule can eliminate small fragments, one molecule of ammonia $\left[\mathrm{GlcN}_{2}+\mathrm{H}-\mathrm{NH}_{3}\right]^{+}$, one molecule of water $\left[\mathrm{GlcN}_{2}+\mathrm{H}-\mathrm{H}_{2} \mathrm{O}\right]^{+}$, or both molecules, [GlcN $\mathrm{N}_{2}+\mathrm{H}$ $\left.-\mathrm{H}_{2} \mathrm{O}-\mathrm{NH}_{3}\right]^{+}$. The formation pathways of the middle-range ions of low abundance (lower than $10 \%$ ) was described as a result of rearrangement. Peak at $m / z 203.1023$ (marked in Figure 18 by an asterisk) had a composition of $\mathrm{C}_{8} \mathrm{H}_{15} \mathrm{~N}_{2} \mathrm{O}_{4}$, i.e., $\left[\mathrm{GlcN}_{2}+\mathrm{H}-\mathrm{C}_{4} \mathrm{H}_{8} \mathrm{O}_{4}\right]^{+}$; its formation was described as a consequent cleavage of one glycosidic bond followed by elimination of the C3-C6 fragment of the second residue (charge-remote elimination). The peaks at $m / z 185.0919$, [GlcN ${ }_{2}+\mathrm{H}-\mathrm{C}_{4} \mathrm{H}_{8} \mathrm{O}_{4}$ $\left.-\mathrm{H}_{2} \mathrm{O}\right]^{+}$and $m / z 167.0814$ [Glc $\left.\mathrm{G}_{2}+\mathrm{H}-\mathrm{C}_{4} \mathrm{H}_{8} \mathrm{O}_{4}-2 \mathrm{H}_{2} \mathrm{O}\right]^{+}$was explained analogously (further elimination of one or two molecules of water, respectively). The peak at $m / z 180.0861$ was assigned to the $\left[\mathrm{GlcN}+\mathrm{H}+\mathrm{H}_{2} \mathrm{O}\right]^{+}$ion. The origin of peaks at $\mathrm{m} / z 174.0756$ and $\mathrm{m} / z 186.0761$ (one and two carbon atoms more than in [GlcN $+\mathrm{H}]^{+}$, respectively) was difficult to understand, possibly they occurred due to unknown skeletal rearrangements different from those known before (loss of internal residues and/or migration of a terminal residue) [57]. In this case, one can suppose that the ions at $\mathrm{m} / \mathrm{z} 186$ and $\mathrm{m} / \mathrm{z} 168$ were formed due to the transfer of the $\mathrm{CH}_{2} \mathrm{CO}$ fragment from one unit to the amino group of the other one followed by cleavage of the glycosidic bond and the loss of one or two molecules of water (in comparison, fragmentation of the protonated molecule of $\mathbf{1 9 b}$ resulted in quite intense peaks of these ions). Activation of the $[\mathrm{M}+2 \mathrm{H}]^{2+}$ ion (c.e $10 \mathrm{eV}$ ) resulted in appearance of the main peak at the same $\mathrm{m} / \mathrm{z}$, but differed from the residual signal by the position of isotopic peaks (see above) along with smaller peaks of the [GlcN $\left.+\mathrm{H}-\mathrm{H}_{2} \mathrm{O}\right]^{+}$and [GlcN $\left.+\mathrm{H}-2 \mathrm{H}_{2} \mathrm{O}\right]^{+}$ions (Figure 19). The peak at $m / z 102.0550$ possessed the composition of $\mathrm{C}_{4} \mathrm{H}_{8} \mathrm{NO}_{2}{ }^{+}$, i.e., it arose from elimination of the neutral fragment of $\mathrm{C}_{2} \mathrm{H}_{4} \mathrm{O}_{2}$ from the glucosamine residue. Small peaks in the range of $m / z$ from 162 to 203 are the same as in $\mathrm{MS}^{2} \mathrm{CID}$ for the $[\mathrm{M}+\mathrm{H}]^{+}$ion, but additional peaks were observed: intense peak at $m / z 190.0707\left(\mathrm{C}_{7} \mathrm{H}_{12} \mathrm{NO}_{5}{ }^{+}\right.$, i.e., in $\mathrm{CO}$ larger than protonated glucosamine residue) and the small peak at $m / z 204.0871\left(\mathrm{C}_{8} \mathrm{H}_{14} \mathrm{NO}_{5}{ }^{+} \text {that corresponds to [GlcNAc }+\mathrm{H}\right]^{+}$, see below). The CID MS ${ }^{2}$ of the $[\mathrm{M}+\mathrm{Na}]^{+}$ion was not described due to its low intensity.

Mass spectra of the negatively charged ions of the studied compounds demonstrated low abundant deprotonated molecules $[\mathrm{M}-\mathrm{H}]^{-}$. As an example, the CID MS ${ }^{2}$ (c.e. $20 \mathrm{eV}$ ) of the ion $[\mathrm{M}-\mathrm{H}]^{-}$ of 20a was considered. The decay of this anion differed from that of protonated molecule because the main fission occurred not at glycosidic bonds. The small peak at $\mathrm{m} / \mathrm{z} 160.0612$ can be considered as a deprotonated link of glucosamine $[\mathrm{GlcN}-\mathrm{H}]^{-}$, i.e., the product of cleavage of two glycosidic bonds, nevertheless, the ion [Glc $\mathrm{N}_{2}-\mathrm{H}^{-}$was not observed. The ions of lower masses occurred due to elimination of molecules of ammonia $\left(m / z 143.0361, \mathrm{C}_{6} \mathrm{H}_{7} \mathrm{O}_{4}{ }^{-}\right)$and water $\left(m / z 142.0508, \mathrm{C}_{6} \mathrm{H}_{8} \mathrm{NO}_{3}{ }^{-}\right)$, and the ion at $m / z 101.0247\left(\mathrm{C}_{4} \mathrm{H}_{5} \mathrm{O}_{3}{ }^{-}\right)$was possibly formed by elimination of the neutral $\mathrm{C}_{2} \mathrm{H}_{5} \mathrm{NO}$ moiety that may correspond to the $\mathrm{O}(1)-\mathrm{C}(1)-\mathrm{C}(2)-\mathrm{N}(2)$ fragment. The main fragment peak at $\mathrm{m} / \mathrm{z}$ $220.0831\left(\mathrm{C}_{8} \mathrm{H}_{14} \mathrm{NO}_{6}{ }^{-}\right)$can be formed only as a result of a cleavage of the $\mathrm{C}-\mathrm{C}$ bond (presumably $\mathrm{C}(4)-\mathrm{C}(5)$ and $\mathrm{C}(5)-\mathrm{O}(5)$ of one of the residues with the retention of one $(1 \rightarrow 6)$-glycosidic bond and the rupture of another one). Small peaks at $m / z 464.1906$ and $m / z 446.1797$ corresponded to elimination of one or two molecules of water. The peak at $m / z 423.1628\left(\mathrm{C}_{16} \mathrm{H}_{27} \mathrm{~N}_{2} \mathrm{O}_{11}{ }^{-}\right)$may be a result of elimination of the $\mathrm{O}(1)-\mathrm{C}(1)-\mathrm{C}(2)-\mathrm{N}(2)$ fragment of one unit. The further elimination of the $\mathrm{C}_{2} \mathrm{H}_{4} \mathrm{O}_{2}$ fragment resulted in formation of $m / z 363.1435\left(\mathrm{C}_{14} \mathrm{H}_{23} \mathrm{~N}_{2} \mathrm{O}_{9}{ }^{-}\right)$anion. The ion at $m / z 280.1053\left(\mathrm{C}_{10} \mathrm{H}_{18} \mathrm{NO}_{8}{ }^{-}\right)$ corresponded to the formal addition of the $\mathrm{C}_{4} \mathrm{H}_{8} \mathrm{O}_{4}$ fragment to the deprotonated glucosamine residue. Formation of this ion was proposed through the rupture of $\mathrm{C}-\mathrm{C}$ and $\mathrm{C}-\mathrm{O}$ bonds in two glucosamine residues with the retention of the third one as a core. It was concluded that primary fragmentation of the negatively charged ions (deprotonated molecules) proceeds in a different way than that of positively charged ones [70]. 


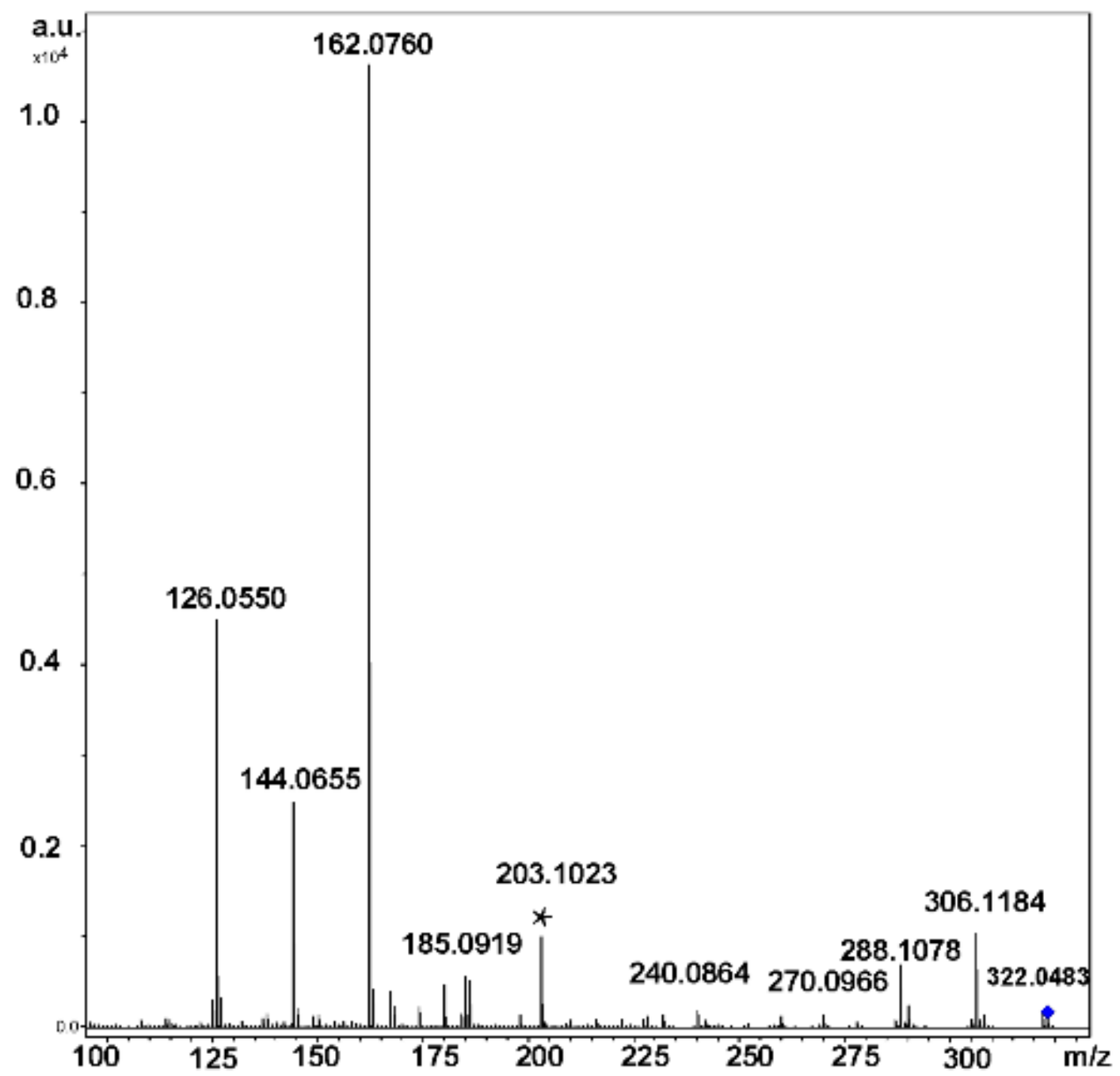

Figure 18. $\mathrm{CID} \mathrm{MS}^{2}(25 \mathrm{eV})$ of the $[\mathrm{M}+\mathrm{H}]^{+}$ion of compound 19a (reproduced from [70] with permission of Springer Nature).

Mass spectra of cyclic oligo- $\mathrm{N}$-acetylglucosamines were similar to those of their acyclic analogs. For example, MS of cyclic dimer of $\mathrm{N}$-acetylglucosamine $19 \mathrm{~b}$ possessed peaks of $[\mathrm{M}+\mathrm{H}]^{+},\left[\mathrm{M}+\mathrm{NH}_{4}\right]^{+}$, $[\mathrm{M}+\mathrm{Na}]^{+}$, and $[\mathrm{M}+\mathrm{K}]^{+}$ions. CID MS ${ }^{2}$ of $[\mathrm{M}+\mathrm{H}]^{+}$ion resulted in a cleavage of glycosidic bonds and formation of the ion at $\mathrm{m} / \mathrm{z} 204.0865\left([\mathrm{GlcNAc}+\mathrm{H}]^{+}\right)$; under c.e. of 10,15 , and $20 \mathrm{eV}$, the peak of this ion was the most intense. Elimination of one, two, and three molecules of water resulted in formation of ions at $m / z 186.0761, m / z ~ 168.0655$, and $m / z 150.0550$, respectively. At c.e. $40 \mathrm{eV}$, the peak at $\mathrm{m} / \mathrm{z}$ $\left.138.0549\left(\mathrm{C}_{7} \mathrm{H}_{8} \mathrm{NO}_{2} \text {, [GlcNAc }+\mathrm{H}-\mathrm{H}_{2} \mathrm{O}-\mathrm{CH}_{2} \mathrm{O}\right]^{+}\right)$became the main one. Two other intense peaks (c.e. $40 \mathrm{eV}$ ) at $m / z 144.0654\left(\mathrm{C}_{6} \mathrm{H}_{10} \mathrm{NO}_{3}\right)$ and $m / z 126.0549\left(\mathrm{C}_{6} \mathrm{H}_{8} \mathrm{NO}_{2}\right)$ were assigned to the fragment ions [GlcNAc $\left.+\mathrm{H}-\mathrm{C}_{2} \mathrm{H}_{4} \mathrm{O}_{2}\right]^{+}$and [GlcNAc $\left.+\mathrm{H}-\mathrm{C}_{2} \mathrm{H}_{4} \mathrm{O}_{2}-\mathrm{H}_{2} \mathrm{O}\right]^{+}$, respectively. Fragmentation of the ion $\left[\mathrm{M}+\mathrm{NH}_{4}\right]^{+}$(c.e. $20 \mathrm{eV}$ ) was similar to that of $[\mathrm{M}+\mathrm{H}]^{+}$. In the range of higher $m / z$, the products of elimination of one ant two molecules of water, $m / z 389.1544$ and $m / z 371.1451$ were found. In CID $\mathrm{MS}^{2}$ (c.e $50 \mathrm{eV}$ ) of metallated molecules of $\mathbf{1 9 b}$, only cleavages of two glycosidic bonds were revealed $\left([\mathrm{GlcNAc}+\mathrm{Na}]^{+}, m / z 226.0686\right.$ and [GlcNAc $+\mathrm{K}^{+}, m / z 242.0355$, respectively), and elimination of $\mathrm{H}_{2} \mathrm{O}$ from these fragments resulted in [GlcNAc $\left.+\mathrm{Na}-\mathrm{H}_{2} \mathrm{O}\right]^{+}, \mathrm{m} / z 208.0575$ and [GlcNAc $\left.+\mathrm{K}-\mathrm{H}_{2} \mathrm{O}\right]^{+}$, $m / z$ 224.0247. For the $[\mathrm{M}+\mathrm{Na}]^{+}$ion, elimination of one and two molecules of water was observed. For cyclic oligomers having from three to seven GlcN units, the same losses were observed. 


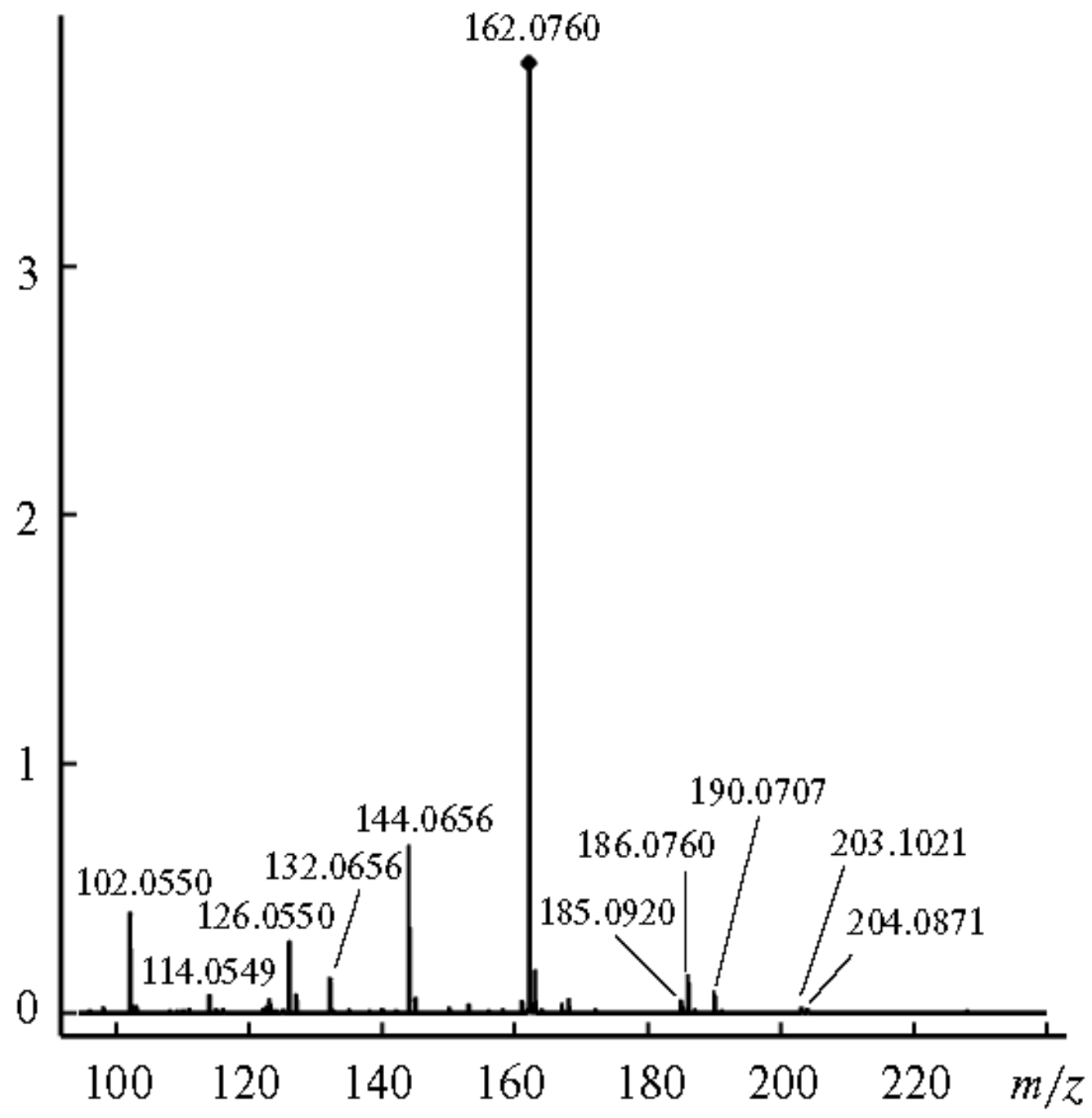

Figure 19. $\mathrm{CID} \mathrm{MS}^{2}(10 \mathrm{eV})$ of the $[\mathrm{M}+2 \mathrm{H}]^{2+}$ ion of compound 19a (reproduced from [70] with permission of Springer Nature).

\subsubsection{Tandem Mass Spectra of Mixed Cyclooligosaccharides}

The aim to reveal characteristic differences in the CID MS² of protonated molecules of isomers 25 and $\mathbf{2 6}$ was claimed in [71]. The possibility that difference in symmetry may result in differences in their fragmentations was hypothesized. Unfortunately, CID MS ${ }^{2}$ of their $[\mathrm{M}+\mathrm{H}]^{+}$ions $(\mathrm{m} / z$ 647.2, c.e. $35 \mathrm{eV}$ ) contained the same signals with slight difference in relative abundance. A small peak at $\mathrm{m} / \mathrm{z}$ 323 related to the disaccharide fragment [GlcGlcN $+\mathrm{H}]^{+}$was observed for both oligosaccharides (note, its relative abundance for $\mathbf{2 5}$ was smaller than that for $\mathbf{2 6}$, its origin for $\mathbf{2 5}$ is unknown).

At the same time, the differences in CID MS ${ }^{2}$ of the doubly charged ions $[\mathrm{M}+2 \mathrm{H}]^{2+}(\mathrm{m} / \mathrm{z} 324.1$, c.e. $10 \mathrm{eV}$ ) were much more prominent (Figure 20a,b). The disaccharide fragments for 25 were the same $(m / z 324$, not $m / z 323$, Figure 20a, inset), whereas similar cleavages for the opposite glycosidic bonds in tetrasaccharide 26 resulted in two of three possible disaccharide fragments $(\mathrm{m} / \mathrm{z} 323$ and $m / z 324$, Figure 20b, inset). For comparison, the $[\mathrm{M}+2 \mathrm{H}]^{2+}$ ion of 21a (Figure 20c) gave an intense peak of the same ion at $m / z 323$ under CID. The highest difference in CID MS ${ }^{2}$ of $[\mathrm{M}+2 \mathrm{H}]^{2+}$ ions for compounds 25 and 26 was found in abundance of $m / z 234.0971\left(\mathrm{C}_{18} \mathrm{H}_{32} \mathrm{~N}_{2} \mathrm{O}_{12}{ }^{2+}\right.$, [Glc $\mathrm{G}_{2} \mathrm{Glc}-\mathrm{H}_{2} \mathrm{O}+$ $2 \mathrm{H}]^{2+}$, calcd. $m / z 234.0972$ ): for 25 , its relative abundance is $0.6 \%$, whereas for 26 it is equal to $33 \%$, so, in more than 50 times higher [71]. Abundances of the corresponding singly charged ion $\mathrm{m} / \mathrm{z} 467.1869$ $\left(\mathrm{C}_{18} \mathrm{H}_{31} \mathrm{~N}_{2} \mathrm{O}_{12}{ }^{+}\right.$, calcd. $\mathrm{m} / z$ 467.1872) were practically equal (11 \% for 25 and $12 \%$ for 26$)$, but the intensities of the peaks at $m / z 485.1977\left(\mathrm{C}_{18} \mathrm{H}_{33} \mathrm{~N}_{2} \mathrm{O}_{13}\right)$ differ in an order of magnitude (5.5\% for 25 and 
$57 \%$ for 26). The data showed that eliminations of a neutral glucose residue (with the formation of a doubly charged ion) and a glucosyl cation (with the formation of a singly charged ion) are impeded for 25, in which the glucose and glucosamine units alters by each other (it was shown in [55] for aminated $\beta-C D$ that protonation occurs at amino group, so, both amino groups are protonated in $[\mathrm{M}+2 \mathrm{H}]^{2+}$ of 25 and 26), but quite possible for 26 where these residues are adjacent. It was supposed that the above processes of cyclooligosaccharide 25 should undergo through drawing together the positively charged centers in a transition state resulting in increase of energy barrier. The choice of activation was shown to be important: at c.e. $35 \mathrm{eV}, \mathrm{CID} \mathrm{MS} \mathrm{MS}^{2}$ of $\left.\mathrm{M}+2 \mathrm{H}\right]^{2+}$ of 25 and 26 contained only peaks of glucosamine unit and its fragmentation products.

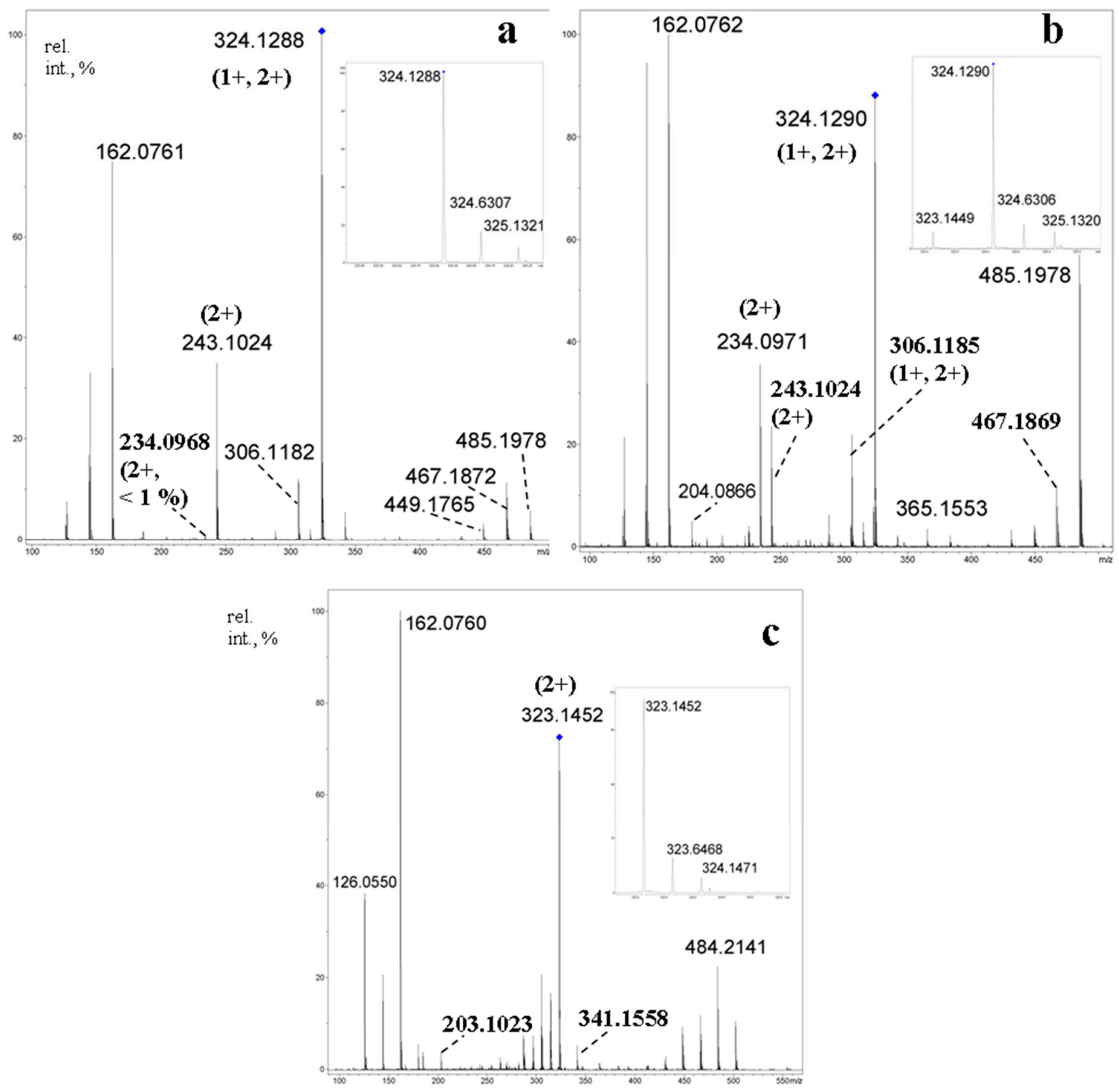

Figure 20. CID MS ${ }^{2}$ of $[\mathrm{M}+2 \mathrm{H}]^{2+}$ ions for cyclotetrasaccharides $25(\mathbf{a}) ; 26(\mathbf{b})$ and, for comparison, 21a (c) $(m / z 324.1$ (a) and (b), $m / z 323.1$ (c), activation energy $10 \mathrm{eV})$. The characteristic peaks $m / z 323$ and $m / z 324$ are given in insets [71].

\subsection{Miscellaneous}

A critical review of traditional methods and recent achievements in the analysis of cyclodextrins and their derivatives is presented in [79]. This paper is devoted to comparison of strength and weakness of current official (European and US Pharmacopoeia) methods with the new advanced techniques 
including mass spectrometry. The aim of the review is to help analysts to decide on changing traditional analytical methods with improved new ones.

Structural description of a synthetic monosubstituted, $\beta$-CD-based glycolipid conjugates tethered through $N$-succinylamido linker was done by high-resolution positive and negative ESI MS [80]. Good agreement was obtained between experimental and calculated isotopic patterns both in positive and negative ion modes. For anions, QqTOF MS² spectra were recorded; only small fragments which originated from side phospholipid chain were observed.

ESI MS was used for the characterization of regioselectively derivatized maltooligosaccharides obtained starting from natural $\beta$-cyclodextrin [81]. For two intermediates, totally acetylated and totally benzoylated heptakis-(6-deoxy-6-bromo)- $\beta-\mathrm{CD}$, ESI HR mass spectra were reported, the only ions observed were $[\mathrm{M}+\mathrm{Na}]^{+}$. For totally benzoylated derivative, QqTOF ESI MS ${ }^{2}$ of $\left[\mathrm{M}+\mathrm{Na}^{+}\right.$was presented and described. Successive losses of $\mathrm{HBr}(80 / 82 \mathrm{Da})$ and $\mathrm{C}_{6} \mathrm{H}_{5} \mathrm{CO}_{2} \mathrm{H}(122 \mathrm{Da})$ occurred. In the low-mass region, abundant ions $m / z 311 / 313,293 / 295,189 / 191$ corresponding to the fragmentation of a single 2,3-di-O-benzoyl-6-deoxy-6-bromo hexose unit along with $m / z 105\left(\mathrm{C}_{6} \mathrm{H}_{5} \mathrm{CO}^{+}\right)$were observed.

An interesting observation concerning charge differentiation in tandem ESI CID mass spectra of C60: $(\gamma-\mathrm{CD})_{2}$ inclusion complex was reported [82]. For positively charged ions [C60: $\left.(\gamma-\mathrm{CD})_{2}+2 \mathrm{H}\right]^{2+}$ and $\left[\mathrm{C} 60:(\gamma-\mathrm{CD})_{2}+2 \mathrm{Na}\right]^{2+}$, only $[(\gamma-\mathrm{CD})+\mathrm{H}]^{+}$or $[\gamma-\mathrm{CD}+\mathrm{Na}]^{+}$, respectively, were registered along with ionized fragments of $\gamma-\mathrm{CD}\left(\left[\mathrm{Gl}_{\mathrm{n}}+\mathrm{H} / \mathrm{Na}\right]^{+}\right)$, whereas for negatively charged ion $\left[\mathrm{C} 60:(\gamma-\mathrm{CD})_{2}-\right.$ $2 \mathrm{H}]^{2-}$, the major fragments gave superposed $\mathrm{C}^{-} 0^{-}$and $[\mathrm{C} 60+\mathrm{H}]^{-}$peak clusters along with minor superposed clusters of deprotonated cyclodextrin $[\gamma-\mathrm{CD}-\mathrm{H}]^{-} /\left[(\gamma-\mathrm{CD})_{2}-2 \mathrm{H}\right]^{2-}$.

A mass spectrometric study of complex, supramolecular object was performed quite recently [83]. Polydisperse, $\alpha$-CD-based $O$-sulfated, polyethylene glycol $\alpha, \omega$-dimethylacrylate-tethered, dipyrenyl-terminated rotaxanes were profiled using Orbitrap ESI MS. Positive ion mode ESI MS² was successfully applied for structure characterization of individual components in a mixture of rotaxanes.

A study of unusual, separately classified compounds was published in [84]. These compounds were no real OSs, but oligomers of carbohydrate nature in which monomer units are linked by ether, not glycosidic (haemiacetal) bond. Two compounds possessing two or three glucofuranose units (eight- and eleven-membered ether cycles) in which hydroxyl groups were protected by 1,2-di-O-isopropylidene and 3-O-dodecyl, were subjected to ESI MS ${ }^{2}$ fragmentation in triple quadrupole instrument using Ar as a collision gas. Schemes of low-energy CID fragmentation were proposed; the main losses were acetone (from isopropylidene) and dodecanol/dodecene (from dodecyl). Ether cycle cleavage also occurred; the authors included this fission as a central part in both schemes.

\section{Conclusions}

For the last three decades, mass spectrometry of cyclic oligosaccharides has achieved great success, especially in the field of gas-phase chemistry of non-covalent, host-guest complexes. Nevertheless, some problems remain unsolved. First, there is no convenient and universal nomenclature of cleavages of cyclic oligosaccharides free of the reducing/nonreducing end formalism. No easy-to-use and reliable methods to differentiate between isomeric cyclic and acyclic oligosaccharides have been proposed. For induced decay of host-guest cyclodextrin complexes, no direct proof of guest-host proton transfer is presented. The boundaries of application of tandem mass spectrometry for determination of positions of substituents in cyclic oligosaccharides are not yet determined. A few works were done concerning fragmentation of negative ions of cyclic oligosaccharides. The methods of activation are now restricted by CID (ESI MS) and LID (MALDI MS), for example, no studies in ECD of multiply charged positive ions of cyclic CDs were carried out. A search of structure effects in complex, mixed cyclic oligosaccharides on their $\mathrm{MS}^{2}$ fragmentation is now in progress; we believe that discoveries will happen concerning these unusual compounds in nearest future.

Author Contributions: Conceptualization, A.O.C.; writing-original draft preparation, A.O.C., Y.E.T., N.E.N.; supervision and critically reviewing the manuscript, Y.E.T., N.E.N.; project administration, N.E.N.; funding 
acquisition, Y.E.T. All the authors critically reviewed the manuscript. All the authors read and approved the final manuscript.

Funding: The research was funded by Russian Science Foundation, grant number 19-43-02023.

Conflicts of Interest: The authors declare no conflict of interest. The funders had no role in the design of the study; in the collection, analyses, or interpretation of data; in the writing of the manuscript, or in the decision to publish the results.

\section{Abbreviations}

a.u.: arbitrarily units, calcd., calculated, ca. circa (about), Cat, cation of a metal, CD(s), cyclodextrin(s), $\mathrm{CE}$, capillary electrophoresis, c.e. collision energy, $\mathrm{CE}_{50}$, collision energy needed for decay of $50 \%$ of the fragmented ion, $\mathrm{CF}(\mathrm{s})$, cyclofructan(s), CID, collision induced dissociation, Da, Dalton, DFT, density functional theory, DHB, dihydroxybenzoic acid, d.p., degree of polymerization, d.s., degree of substitution. EI, electron ionization, ESI, electrospray ionization, FAB, fast atom bombardment, Fru, fructose, FT, Fourier-transform, GPC, gel-permeation chromatography, $\mathrm{HBCD}$, hydroxybutyrated $\beta$-cyclodextrin, $\mathrm{HCD}$, higher collision dissociation, $\mathrm{HR}$, high-resolution, Glc, glucose, GlcN, glucosamine, GlcNAc, N-acetylglucosamine, Hex, hexose, ICD, in-source decay, ICR, ion cyclotron resonance, IS, ion spray, IMS, ion mobility spectrometry, LID, laser-induced decay, LIT, linear ion trap, M, molecule of an analyte, MALDI, matrix-assisted, laser desorption/ionization, NMR, nuclear magnetic resonance, OS(s), oligosaccharide(s), OPG, osmoregulated periplasmic glucan, MS, mass spectrometry, $\mathrm{MS}^{2}$, second-order (tandem) mass spectrometry (or spectrum), NMR, nuclear magnetic resonance, QqTOF, hybrid quadrupole, time-of-flight instrument, PQD, pulsed-Q-dissociation, PSD, post-source decay, rel. int., relative intensity, TABCD, totally acetylated $\beta$-cyclodextrin, Th, Thompson (Da/z), TOF, time-of-flight, Trp, tryptophan, 5MTA, 5-methoxytriptamine.

\section{References}

1. Crini, G. Review: A history of cyclodextrins. Chem. Rev. 2014, 114, 10940-10975. [CrossRef] [PubMed]

2. Gattuso, G.; Nepogodiev, S.A.; Stoddart, J.F. Synthetic cyclic oligosaccharides. Chem. Rev. 1998, 98, $1919-1958$. [CrossRef] [PubMed]

3. Xie, J.; Bogliotti, N. Synthesis and Applications of carbohydrate-derived macrocyclic compounds. Chem. Rev. 2014, 114, 7678-7739. [CrossRef] [PubMed]

4. Mura, P. Analytical techniques for characterization of cyclodextrin compexes in aqueous solution: A review. Journ. Pharm. Biomed. Anal. 2014, 101, 238-250. [CrossRef] [PubMed]

5. Zhang, J.; Ma, P.X. Cyclodextrin-based supramolecular systems for drug delivery: Recent progress and future perspective. Adv. Drug Delivery Rev. 2013, 65, 1215-1233. [CrossRef] [PubMed]

6. Jambhekar, S.S.; Breen, P. Cyclodextrins in pharmaceutical formulations. I: Structure and physicochemical properties, formation of complexes, and types of complex. Drug Discovery Today 2016, 21, 356-362. [CrossRef] [PubMed]

7. Ştefănescu, R.; Stanciu, G.D.; Luca, A.; Caba, I.C.; Tamba, B.I.; Mihai, C.T. Contributions of mass spectrometry to the identification of low molecular weight molecules able to reduce the toxicity of amyloid- $\beta$-peptide to cell cultures and transgenic mouse models of Alzheimer's disease. Molecules 2019, 24, 1167. [CrossRef] [PubMed]

8. Cole, R.B. (Ed.) Electrospray and MALDI Mass Spectrometry: Fundamentals, Instrumentation, Practicalities, and Biological Applications, 2nd ed.; Wiley: Hoboken, NJ, USA, 2010.

9. Zaya, J. Mass spectrometry of oligosaccharides. Mass Spectrom. Rev. 2004, 23, 161-227. [CrossRef]

10. Voyksner, R.; Williams, F.P.; Smith, C.S.; Koble, D.L.; Seltzman, H.H. Analysis of cyclodextrins using fast atom bombardment/mass spectrometry and tandem mass spectrometry. Biol. Mass Spectrom. 1989, 18, 1071-1078. [CrossRef]

11. Huang, E.C.; Henion, J.D. Characterization of cyclodextrins using ion-evaporation atmospheric-pressure ionization mass spectrometry. Rapid Commun. Mass Spectrom. 1990, 4, 467-471. [CrossRef]

12. Metzger J., W.; Jung, M.; Schmalzing, D.; Bayer, E.; Schurig, V. Analysis of cyclomalto-oligosaccharides (cyclodextrins) and derivatives thereof by ion-spray mass spectrometry. Carbohydr. Res. 1991, 222, $23-35$. [CrossRef]

13. Wei, W.; Chu, Y.; He, X.; Ding, C. Quantifying non-covalent binding affinity using mass spectrometry: A systematic study on complexes of cyclodextrins with alkali metal cations. Rapid Commun. Mass Spectrom. 2015, 29, 927-936. [CrossRef] [PubMed] 
14. Kellersberger, K.A.; Dejsupa, C.; Liang, Y.; Pope, R.M.; Dearden, D.V. Gas-phase studies of ammoniumcyclodextrin compounds using Fourier transform ion cyclotron resonance. Internat. J. Mass Spectrom. 1999, 193, 181-195. [CrossRef]

15. Yamamura, H.; Iwata, T.; Kawai, M.; Sato, A. Electrospray ionization tandem mass spectrometry determined regioisomeric structures of disubstituted $\beta$-cyclodextrin derivatives. Eur. J. Mass Spectrom. 2006, 12, 37-42. [CrossRef] [PubMed]

16. Kellner, I.D.; Drewello, T. Influence of single skimmer versus dual funnel transfer on the appearance of ESI-generated $\mathrm{LiCl}$ cluster/ $\beta$-cyclodextrin inclusion complexes. J. Am. Soc. Mass Spectrom. 2015, 26, 1328-1337. [CrossRef] [PubMed]

17. Berland, K.; Renauld J., B.; Mayer P., M. Utilizing ion mobility and tandem mass spectrometry to evaluate the structure and behaviour of multimeric cyclodextrin complexes. Can. J. Chem. 2015, 93, 1313-1319. [CrossRef]

18. Kralj, B.; Šmidovnik, A.; Kobe, J. Mass spectrometric investigations of $\alpha$ - and $\beta$-cyclodextrin complexes with ortho-, meta-, and para-coumaric acids by negative mode electrospray ionization. Rapid Commun. Mass Spectrom. 2009, 23, 171-180. [CrossRef]

19. Carroll, J.A.; Penn, S.G.; Fannin, S.T.; Wu, J.; Cancilla, M.T.; Green, M.K.; Lebrilla, C.B. A dual vacuum chamber Fourier transform mass spectrometer with rapidly interchangeable LSIMS, MALDI, and ESI sources: Initial results with LSIMS and MALDI. Anal. Chem. 1996, 68, 1798-1804. [CrossRef]

20. Mele, A.; Malpezzi, L. Noncovalent association phenomena of 2,3-dihydroxybenzoic acid with cyclic and linear oligosaccharides. A matrix-assisted laser desorption/ionization time-of-flight mass spectrometric and X-ray crystallographic study. J. Am. Soc. Mass Spectrom. 2000, 11, 228-236. [CrossRef]

21. Shizuma, M.; Takai, Y.; Kawamura, M.; Takeda, T.; Sawada, M. Complexation characteristics of permethylated cycloinulohexaose, cycloinuloheptaose, and cycloinulooctaose with metal cations. J. Chem. Soc. Perkin Trans. 2001, 2, 1306-1314. [CrossRef]

22. Wang, C.; Yang, S.H.; Wang, J.; Kroll, P.; Shug, K.A.; Armstrong, D.W. Study of complexation between cyclofructans and alkali metal cations by electrospray ionization mass spectrometry and density functional theory calculations. Int. J. Mass Spectrom. 2010, 291, 118-127. [CrossRef]

23. Wang, L.; Li, Y.; Yao, L.; Sun, C.; Zheng, S.; Pan, Y. Evaluation and determination of the cyclofructans-amino acid complexes binding pattern by electrospray ionizatiom mass spectrometry. J. Mass Spectrom. 2014, 49, 1043-1049. [CrossRef] [PubMed]

24. Sun, W.; Cui, M.; Liu, S.; Song, F.; Elkin, Y.N. Electrospray ionization mass spectrometry of cyclodextrin complexes with amino acids in incubated solution and in eluates of gel permeation chromatography. Rapid Commun. Mass Spectrom. 1998, 12, 2016-2022. [CrossRef]

25. Wei, W.; Chu, Y.; Ding, C. Gas-phase binding of noncovalent complexes between $\alpha$-cyclodextrin and amino acids investigated by mass spectrometry. Analyt. Lett. 2014, 47, 2221-2237. [CrossRef]

26. Chen, Y.; Zuo, Z.; Dai, X.; Xiao, P.; Fang, X.; Wang, X.; Wang, W.; Ding, C.-F. Gas-phase complexation of $\alpha-/ \beta$-cyclodextrin with amino acids studied by ion-mobility-mass spectrometry and molecular dynamics simulations. Talanta 2018, 186, 1-7. [CrossRef] [PubMed]

27. Barylyuk, K.; Balabin, R.M.; Grúnstein, D.; Kikkeri, R.; Frankevich, V.; Seeberger, P.H.; Zenobi, R. What happens to hydrophobic interactions during transfer from the solution to the gas phase? The case of electrospray-based soft ionization methods. J. Am. Soc. Mass Spectrom. 2011, 22, 1167-1177. [CrossRef] [PubMed]

28. Lebrilla, C.B. The gas-phase chemistry of cyclodextrin inclusion complexes. Acc. Chem. Res. 2001, 34, 653-661. [CrossRef] [PubMed]

29. Yu, X.; Yao, Z.-P. Chiral recognition and determination of enantiomeric excess by mass spectrometry: A review. Anal. Chim. Acta 2017, 968, 1-20. [CrossRef]

30. Przybylski, C.; Bonnet, V.; Cèzard, C. Probing the common alkali metal affinity of native and variously methylated $\beta$-cyclodextrins by combining electrospray tandem mass spectrometry and molecular modeling. Phys. Chem. Chem. Phys. 2015, 17, 19288-19305. [CrossRef]

31. Chankvetadze, B.; Endresz, G.; Blaschke, G.; Juza, M.; Jakubetz, H.-J.; Schurig, V. Analysis of charged cyclomaltooligosaccharide (cyclodextrin) derivatives by ion-spray, matrix-assisted laser desorption/ionization time-of-flight and fast atom bombardment mass spectrometry, and by capillary electrophoresis. Carbohydr. Res. 1996, 287, 139-155. [CrossRef] 
32. Madhusudanan, K.P. Multiple lithium exchange under lithium cationization of cyclodextrins. J. Mass Spectrom. 2003, 38, 409-416. [CrossRef] [PubMed]

33. Franski, R.; Gierczyc, B.; Schroeder, G.; Beck, S.; Springer, A.; Linscheid, M. Mass Spectrometric decompositions of cationized $\beta$-cyclodextrin. Carbohydr. Res. 2005, 340, 1567-1572. [CrossRef] [PubMed]

34. He, X.; Wei, W.; Chu, Y.; Liu, Z.; Ding, C. Investigation of non-covalent complexes of cyclodextrins with $\mathrm{Li}^{+}$ in gas phase by mass spectrometry. Chin. J. Chem. Phys. 2013, 26, 287-294. [CrossRef]

35. Kostyukevich, Y.T.; Kononikhin, A.S.; Bugrova, A.E.; Starodubtseva, N.L.; Popov, I.; Nikolaev, E. Investigation of ion-molecular complexes of beta-cyclodextrin with proteins and metals in gas phase. Macroheterocycles 2017, 10, 110-116. [CrossRef]

36. Sforza, S.; Galaverna, G.; Corradini, R.; Dossena, A.; Marchelli, R. ESI-mass spectrometry analysis of unsubstituted and disubstituted $\beta$-cyclodextrins: Fragmentation mode and identification of the AB, AC, AD regioisomers. J. Am. Soc. Mass Spectrom. 2003, 14, 124-135. [CrossRef]

37. Jacquet, R.; Elfakir, C.; Lafosse, M. Characterization of new methylated beta-cyclodextrin with low degree of substitution by electrospray ionization mass spectrometry and liquid chromatography/mass spectrometry. Rapid Commun. Mass Spectrom. 2005, 19, 3097-3102. [CrossRef] [PubMed]

38. Carroll, J.A.; Ngoka, L.; Beggs, C.G.; Lebrilla, C.B. Liquid secondary ion mass spectrometry/Fourier transform mass spectrometry of oligosaccharide anions. Anal. Chem. 1993, 65, 1582-1587. [CrossRef]

39. Wang, L.; Chai, Y.; Sun, C.; Armstrong, D.W. Complexation of cyclofructans with transition metal ions studied by electrospray ionization mass spectrometry and collision-induced dissociation. Int. J. Mass Spectrom. 2012, 323-324, 21-27. [CrossRef]

40. Domon, B.; Costello, C.E. A systematic nomenclature for carbohydrate fragmentations in FAB-MS/MS spectra of glycoconjugates. Glycoconjugate J. 1988, 5, 397-409. [CrossRef]

41. Pfeffer, P.E.; Osman, S.F.; Hotchkiss, A.; Bhagwat, A.A.; Keister, D.L.; Valentine, K.M. Cyclolaminarinose. A new biologically active $\beta-(1 \rightarrow 3)$ cyclic glucan. Carbohydr. Res. 1996, 296, 23-37. [CrossRef]

42. Bhagwat, A.A.; Mithőfer, A.; Pfeffer, P.E.; Kraus, C.; Spickers, N.; Hotchkiss, A.; Ebel, J.; Keister, D.L. Further studies of the role of cyclic $\beta$-glucans in symbiosis. An $n d v C$ mutant of Bradyrhizobium japonicum synthesizes cyclodekakis-(1 $\rightarrow 3)-\beta$-glucosyl. Plant. Physiol. 1999, 119, 1057-1064. [CrossRef] [PubMed]

43. Chizhov, A.O.; Dell, A.; Morris, H.R.; Reason, A.J.; Haslam, S.M.; McDowell, R.A.; Chizhov, O.S.; Usov, A.I. Structural analysis of laminarans by MALDI and FAB mass spectrometry. Carbohydr. Res. 1998, 310, $203-210$. [CrossRef]

44. Dell, A.; York, S.; McNeil, M.; Darvill, A.G.; Albersheim, P. The cyclic structure of $\beta$-D-(1 $\rightarrow 2)$-linked D-glucans secreted by Rhizobia and Agrobacteria. Carbohydr. Res. 1983, 117, 185-200. [CrossRef]

45. Talaga, P.; Stahl, B.; Wieruszeski, J.-M.; Hillenkamp, F.; Tsuyumu, S.; Lippens, G.; Bohin, J.-P. Cell-associated glucans of Bukholderia solanacearum and Xantomonas campestris pv. citri: A new family of periplasmic glucans. J. Bacteriol. 1996, 178, 2263-2271.

46. Jung, Y.; Park, H.; Cho, E.; Jung, S. Strucural analyses of novel glycerophosphorylated $\alpha$-cyclosophorohexa decaoses isolated from X. campestris pv. campestris. Carbohydr. Res. 2005, 340, 673-677. [CrossRef] [PubMed]

47. Cho, E.; Kwon, C.; Lee, S.; Tahir, M.N.; Park, S.; Jung, S. Biotinylation of the rhizobial cyclic $\beta$-glucans and succinoglycans crucial for symbiosis with legumes. Carbohydr. Res. 2014, 389, 141-146. [CrossRef] [PubMed]

48. Choi, S.-S.; Lee, H.M.; Jang, S.; Shin, J. Comparison of ionization behaviors of ring and linear carbohydrates in MALDI-TOF MS. Internat. J. Mass Spectrom. 2009, 279, 53-58. [CrossRef]

49. Bashir, S.; Giannakopulos, A.E.; Derrick, P.J.; Critchley, P.; Bottrill, A.; Padley, H.D. Matrix-assisted laser desorption/ionisation time-of-flight mass spectrometry. A comparison of fragmentation patterns of linear dextran obtained by in-source decay, post-source decay and collision-induced dissociation and stability of linear and cyclic glucans studied by in-source decay. Eur. J. Mass Spectrom. 2004, 10, 109-120.

50. Przybylski, C.; Bonnet, V. Discrimination of cyclic and linear oligosaccharides by tandem mass spectrometry using collision-induced dissociation (CID), pulsed-Q-dissociation, and the higher energy C-trap dissociation modes. Rapid Comm. Mass Spectrom. 2013, 27, 75-87. [CrossRef]

51. Vrkic, A.K.; O’Hair, A.J.; Lebrilla, C.B. Unusual covalent bond-breaking reactions of $\beta$-cyclodextrin inclusion complexes of nucleobases/nucleosides and related guest molecules. Eur. J. Mass Spectrom. 2003, 9, 563-577. [CrossRef] 
52. Mele, A.; Panzeri, W.; Selva, A.; Mauri, P. Fast atom bombardment, electrospray, ionspray and tandem mass spectrometry of 1 : $1 \beta$-cyclodextrin/5-methoxytryptamine hydrochloride host-guest complex: Host protonation and fragmentation due to guest deamination. Eur. J. Mass Spectrom. 2000, 6, 169-174. [CrossRef]

53. Cai, Y.; Tarr, M.A.; Xu, G.; Yalcin, T.; Cole, R.B. Dication induced stabilization of gas-phase ternary betacyclodextrin inclusion complexes observed by electrospray mass spectrometry. J. Am. Soc. Mass Spectrom. 2003, 14, 449-459. [CrossRef]

54. Tripodo, G.; Wischke, C.; Neffe, A.T.; Lendlein, A. Efficient synthesis of pure monotosylated beta-cyclodextrin. Carbohydr. Res. 2013, 381, 59-63. [CrossRef] [PubMed]

55. Yamagaki, T.; Sugahara, K.; Watanabe, T. Amino and acetamide functional group effects on the ionization and fragmentation of sugar chains in positive-ion mass spectrometry. J. Am. Soc. Mass Spectrom. 2014, 25, 95-103. [CrossRef] [PubMed]

56. Kovačik, V.; Pātoprsty, V.; Havliček, V.; Kovač, P. Matrix-assisted laser desorpton/ionization and electrospray ionization mass spectrometry: Sodium cationized oligosaccharides do not exhibit "internal-residue" loss rearrangement. Eur. Mass Spectrom. 1998, 4, 417-420. [CrossRef]

57. Wuhrer, M.; Deelder, A.M.; van der Burgt, Y.E.M. Mass spectrometric glycan rearrangements. Mass Spectrom. Rev. 2011, 30, 664-680. [CrossRef] [PubMed]

58. Donkuru, M.; Chitanda, J.M.; Verrall, R.E.; El Aneed, A. Multi-stage tandem mass spectrometric analysis of novel $\beta$-cyclodextrin-substituted and novel bis-pyridinium gemini surfactants designed as nanomedical drug delivery agents. Rapid Comm. Mass Spectrom. 2014, 28, 757-772. [CrossRef]

59. Takashima, Y.; Osaki, M.; Harada, A. Cyclodextrin-initiated polymerization of cyclic esters in bulk: Formation of polyester-tethered cyclodextrins. J. Am. Chem. Soc. 2004, 126, 13588-13589. [CrossRef]

60. Shen, J.; Hao, A.Y.; Du, G.Y.; Zhang, H.C.; Sun, H.Y. A convenient preparation of 6-oligo(lactic acid) cyclomaltohexaose as kinetically degradable derivative for controlled release of Amoxicillin. Carbohydr. Res. 2008, 343, 2517-2522. [CrossRef]

61. Peptu, C.; Nicolescu, A.; Peptu, C.A.; Harabagiu, V.; Simionescu, B.C.; Kowalczuk, M. Mass spectrometry characterization of 3-OH butyrated $\beta$-cyclodextrin. J. Polym. Sci., Part. A: Polym. Chem. 2010, 48, 5581-5592. [CrossRef]

62. Miao, Y.; Rousseau, C.; Mortreux, A.; Martin, P.; Zinck, P. Access to new carbohydrate-functionalized polylactides via organocatalyzed ring-opening polymerization. Polymer 2011, 52, 5018-5026. [CrossRef]

63. Peptu, C.; Balan-Porcarasu, M.; Šiškova, A.M.; Škultety, L'.; Mosnaček, J. Cyclodextrin tethered with oligolactides-Green synthesis and structural assessment. Beilstein J. Org. Chem. 2017, 13, 779-792. [CrossRef] [PubMed]

64. Xu, Z.; Liu, S.; Liu, H.; Yang, C.; Kang, Y.; Wang, M. Unimolecular micelles of amphiphilic cyclodextrin-core star-like block copolymers for anticancer drug delivery. Chem. Commun. 2010, 51, 15568-15771. [CrossRef] [PubMed]

65. Peptu, C.; Harabagiu, V. Tandem mass spectrometry characterization of esterified cyclodextrins. Dig. J. Nanomater. Biostruct. 2013, 8, 1551-1561.

66. Peptu, C.; Danchenko, M.; Škultèty, L'.; Mosnaček, J. Structural architectural features of cyclodextrin oligoesters revealed by fragmentation mass spectrometry analysis. Molecules 2018, 23, 2259. [CrossRef] [PubMed]

67. Peptu, C.; Kwiecien, I.; Harabagiu, V.; Simionescu, B.C.; Kowalczuk, M. Modification of $\beta$-cyclodextrin through solution ring-opening oligomerization of $\beta$-butyrolactone. Cellulose Chem. Technol. 2014, 48, 1-10.

68. Kieken, F.; West, C.; Keddadouche, K.; Elfakir, C.; Choisnard, L.; Gese, A.; Wouessidjewe, D. Characterization of complex amphiphilic cyclodextrin mixturtes by high-performance liquid chromatography and mass spectrometry. J. Chromatogr. A 2008, 1189, 385-391. [CrossRef]

69. Normand, M.; Kirillov, E.; Carpentier, J.-F.; Guillaume, S.M. Cyclodextrin-centered polyesters. Controlled ring-opening polymerization of cyclic esters from $\beta$-cyclodextrin-diol. Macromolecules 2012, 45, 1122-1130. [CrossRef]

70. Chizhov, A.O.; Gening, M.L.; Pinsker, O.A.; Yudina, O.N.; Tsvetkov, Y.E.; Nifantiev, N.E. Gas-phase fragmentation studies of cyclic oligo- $(1 \rightarrow 6)-\beta$-D-glucosamines by electrospray mass spectrometry using a hybrid high-resolution mass spectrometer. Russ. Chem. Bull. 2018, 67, 144-149. [CrossRef] 
71. Chizhov, A.O.; Gening, M.L.; Pinsker, O.A.; Tsvetkov, Y.E.; Nifantiev, N.E. Isomeric effects in collisionally-induced dissociation of $\beta-(1 \rightarrow 6)$-linked cyclic tetrasaccharides of the Glc $p_{2}$ Glc $p N_{2}$ composition. Mass-Spectrometria 2018, 15, 262-266, (in Russ., Engl. Transl. in J. Analyt. Chem., in press).

72. Gening, M.L.; Titov, D.V.; Grachev, A.A.; Gerbst, A.G.; Yudina, O.N.; Chizhov, A.O.; Tsvetkov, Y.E.; Nifantiev, N.E. Synthesis, NMR and conformational studies of cyclic oligo-( $1 \rightarrow 6)-\beta$-D-glucosamines. Eur. J. Org. Chem. 2010, 13, 2465-2475. [CrossRef]

73. Gening, M.L.; Tsvetkov, Y.E.; Pier, G.B.; Nifantiev, N.E. Synthesis of oligo- $\beta-(1 \rightarrow 6)$-glucosamines corresponding to the fragments of the surface polysaccharide of Staphylococcus aureus. Carbohydr. Res. 2007, 342, 567-575. [CrossRef] [PubMed]

74. Grachev, A.A.; Gerbst, A.G.; Gening, M.L.; Titov, D.V.; Yudina, O.N.; Tsvetkov, Y.E.; Shashkov, A.S.; Pier, G.B.; Nifantiev, N.E. NMR and conformational studies of linear and cyclic oligo-( $1 \rightarrow 6)-\beta$-D-Glucosamines. Carbohydr. Res. 2011, 346, 2499-2510. [CrossRef] [PubMed]

75. Gening, M.L.; Titov, D.V.; Cecioni, S.; Audfray, A.; Gerbst, A.G.; Tsvetkov, Y.E.; Krylov, V.B.; Imberty, A.; Nifantiev, N.E.; Vidal, S. Synthesis of multivalent carbohydrate-centered glycoclusters as nanomolar ligands of the bacterial lectin LecA from Pseudomonas aeruginosa. Chem. Eur. J. 2013, 19, 9272-9275. [CrossRef] [PubMed]

76. Gening, M.L.; Tsvetkov, Y.E.; Titov, D.V.; Gerbst, A.G.; Yudina, O.N.; Grachev, A.A.; Shashkov, A.S.; Vidal, S.; Imberty, A.; Saha, T.; et al. Linear and cyclic oligo- $\beta-(1 \rightarrow 6)$-D-glucosamines: Synthesis, conformations and applications for design of a vaccine and oligodentate glycoconjugates. Pure Appl. Chem. 2013, 85, 1879-1891. [CrossRef]

77. Saha, T.; Roy, A.; Gening, M.L.; Titov, D.V.; Gerbst, A.G.; Tsvetkov, Y.E.; Nifantiev, N.E.; Talukdar, P. Cyclo-oligo-(1 $\rightarrow 6)$ - $\beta$-D-glucosamine based artificial channels for tunable transmembrane ion transport. Chem. Commun. 2014, 50, 5514-5516. [CrossRef]

78. Roy, A.; Saha, T.; Gening, M.L.; Titov, D.V.; Gerbst, A.G.; Tsvetkov, Y.E.; Nifantiev, N.E.; Talukdar, P. Trimodal control of ion transport activity on cyclo-oligo- $(1 \rightarrow 6)-\beta$-D-glucosamine based artificial ion transport systems. Chem. Eur. J. 2015, 21, 17445-17452. [CrossRef] [PubMed]

79. Szente, L.; Szeman, J.; Sohajda, T. Analytical characterization of cyclodextrins: History, official methods and recommended new techniques. Journ. Pharm. Biomed. Anal. 2016, 130, 347-365. [CrossRef]

80. Moutard, S.; Djedaïni-Pilard, F.; Meudal, S.; Luijen, W.; Perly, B.; Pilard, S. Structural identification of new glycolipids based on cyclodextrin using high-resolution positive and negative electrospray ionization mass spectrometry. Rapid Commun. Mass Spectrom. 2003, 17, 2535-2540. [CrossRef]

81. Lesur, D.; Gassama, A.; Moreau, V.; Djedani-Pilard, F.; Brique, A.; Pilard, S. Electrospray ionization mass spectrometry: A key analytical tool for the characterization of regioselectively derivatized maltooligosaccharides obtained starting from natural $\beta$-cyclodextrin. Rapid Commun. Mass Spectrom. 2006, 20, 747-754. [CrossRef]

82. Greisch, J.-F.; Kritsoglou, S.; Leyh, B.; De Pauw, E. Mass spectrometric study of the ionized C60: $(\gamma \text {-cyclodextrin })_{2}$ inclusion complex by collision induced dissociation. J. Mass Spectrom. 2008, 43, 242-250. [CrossRef] [PubMed]

83. Przybylski, C.; Jarroux, N. Analysis of polydisperse polyrotaxane based on poly(ethylene oxide) and $\alpha$-cyclodextrins using nanoelectrospray and LTQ-orbitrap. Analyt. Chem. 2011, 83, 8460-8467. [CrossRef] [PubMed]

84. Banoub, J.; Tibault, P.; Gouèth, P.Y.; Ronco, G.; Villa, P. Electrospray tandem mass spectrometry of a novel series of amphipathic functionalized ether-linked di- and trisaccharides and cyclic oligosaccharides. J. Mass Spectrom. 1997, 32, 109-121. [CrossRef]

(C) 2019 by the authors. Licensee MDPI, Basel, Switzerland. This article is an open access article distributed under the terms and conditions of the Creative Commons Attribution (CC BY) license (http://creativecommons.org/licenses/by/4.0/). 